\title{
Eco-friendly product development strategy: antecedents, outcomes, and contingent effects
}

\author{
Constantine S. Katsikeas ${ }^{1}$ - Constantinos N. Leonidou ${ }^{1} \cdot{\text { Athina } \text { Zeriti }^{2}}^{2}$
}

Received: 3 February 2015 / Accepted: 7 December 2015 / Published online: 7 January 2016

(C) The Author(s) 2016. This article is published with open access at Springerlink.com

\begin{abstract}
Integrating sustainability aspects into product development has long been recognized as a strategic priority for practitioners. Yet the literature reports mixed results on the product development effectiveness outcomes of sustainable product development strategies, while scant research has investigated how companies integrate environmental aspects into product development. This study develops a model that integrates effectiveness-enhancing outcomes and organizational inputs of eco-friendly product development strategies. Using questionnaire responses from firms from multiple industries, supplemented with lagged primary product development performance data, we find that top management commitment and corporate environmental support policies can facilitate eco-friendly product development strategies, while environmental performance incentives do not. In turn, the adoption of such strategies has a positive effect on firms' product development effectiveness. This effect weakens when business conditions are highly complex but tends to become stronger with increasing levels of munificence in the business environment. These findings have important implications for practitioners and researchers that are discussed.
\end{abstract}

Constantine S. Katsikeas

csk@lubs.leeds.ac.uk

Constantinos N. Leonidou

cl@lubs.leeds.ac.uk

Athina Zeriti

Athina.zeriti@durham.ac.uk

1 Leeds University Business School, University of Leeds, Maurice Keyworth Building, Leeds LS2 9JT, UK

2 Business School, Durham University, Queen's Campus, University Boulevard, Thornaby, Stockton on Tees TS17 6BH, UK
Keywords Sustainability · Green · Product development · Top management commitment · Business environment . Performance · Innovation

As a result of growing ecological challenges and mounting pressures to consider the impact of human activities on the natural environment, firms around the world have increasingly adopted more sustainable business and marketing practices (Kotler 2011). Many companies have strategically aligned themselves with the interests of stakeholders and the marketoriented product needs and wants of customers pertaining to sustainability issues (Hult 2011). A popular marketing response in this changing market landscape has been to modify existing or introduce new product and production practices to reduce ecological impact and enhance environmental performance (Cronin et al. 2011). Although accounting for product development effects on the natural environment adds complexity to firm processes, such practices are visible, can easily be communicated to stakeholders, and contribute to the firm's environmental image (Dangelico and Pujari 2010). Given that the introduction of eco-friendly products enables firms to meet environmental imperatives, build competitive advantage, and propel future growth (Nidumolu et al. 2009), sustainable product development activities are expected to grow in importance in the future (Varadarajan 2015).

Practitioner interest in greening product design and development has generated new research challenges in the marketing, supply chain management, and product development academic fields. To shed light on the subject, scholars have worked to understand why and how companies engage in such product development practices, and the topic has received considerable research attention under various headings: sustainable innovations orientation (e.g., Varadarajan 2015), ecodesign practices (e.g., Sarkis et al. 2010), green product 
innovation (e.g., Dangelico and Pujari 2010), green product development (e.g., Chen 2001), green product programs (e.g., Leonidou et al. 2013), environmental new product development (e.g., Pujari et al. 2003), and environmentally conscious product strategies (e.g., Pujari and Wright 1996). Unquestionably, this stream of studies has contributed to the understanding of the importance of sustainable product practices in business and marketing.

However, despite the considerable progress to date, two major issues in the literature warrant consideration. First, in the past two decades significant debate has centered on whether environmental strategies are beneficial for business performance. Surprisingly, despite repeated calls (e.g., Cronin et al. 2011; Varadarajan 2015), few studies have examined the performance outcomes of eco-friendly product strategies (e.g., Dangelico et al. 2013; Leonidou et al. 2013), and even fewer have focused specifically on product development outcomes (e.g., González-Benito and González-Benito 2005). Even more important is that the limited empirical research on the topic reports conflicting results, preventing scholarship and practical advancement in the field. For example, while some studies show positive effects of green strategies on product development performance (e.g., Fraj-Andrés et al. 2009), others find no relationship between the two (e.g., Dangelico et al. 2013), and still others reveal a negative link (e.g., González-Benito and González-Benito 2005). Such mixed findings suggest not only that the eco-friendly product development strategy-effectiveness link is complex and poorly understood but also that such product development practices may not enhance performance under all circumstances. It is thus important to evaluate this relationship to identify conditioning factors (e.g., Aragon-Correa and Sharma 2003).

Second, the bulk of research on the drivers of eco-friendly product practices has focused on either corporate sustainability (e.g., Banerjee et al. 2003; Rueda-Manzanares et al. 2008) or eco-friendly product issues at the individual project level (e.g., Pujari 2006). Scant attention has been devoted to how firms can integrate sustainability aspects into product development, particularly at the program or organizational level (Dangelico and Pujari 2010; Eppinger 2011). ${ }^{1}$ This lack of empirical work limits understanding of how firms can support and strengthen their eco-friendly product strategies and the factors conducive to such strategies' development and success. Organization-level product development is likely driven by factors that are different from those focused on other levels within the firm (e.g., project) (Chen et al. 2010). Such studies can enhance generalizability due to their focus on issues, intricacies, and challenges relevant to the firm's overall product

\footnotetext{
${ }^{1}$ Program-level studies focus on a firm's overall product development practices, while project-based studies center on issues pertaining to a specific (successful or failed) product development project (e.g., Koufteros et al. 2002). In the literature, program and organization levels reflect the same unit of analysis (e.g., Chen et al. 2010).
}

development (Koufteros et al. 2002). The absence of research on organization-based eco-friendly product development requires immediate attention, as managers are under increasing pressure from multiple, and often interacting, stakeholders to integrate sustainability into their firms' marketing activities.

Against these backdrops, we develop and empirically test a model of drivers and outcomes of eco-friendly product development strategy. Our research makes three contributions to knowledge in this increasingly important stream of research. First, using primary data collected at two points in time in a cross-industry sample, we provide a rigorous answer as to whether the extent to which firms deploy eco-friendly product development strategies significantly affects product development effectiveness. Our data collection design enables us to test hypotheses on the performance outcomes of eco-friendly product development strategies and to rule out alternative causal explanations. The results support the premise that eco-friendly product development strategies provide product development effectiveness benefits for firms. In fact, our posthoc analyses show that firms stand to gain an improvement between 21.3 and $31 \%$ in their product development effectiveness, when such strategies are robustly executed.

Second, this study responds to repeated calls in the sustainability literature (e.g., Aragon-Correa and Sharma 2003; Dangelico et al. 2013) to explore whether the presence of eco-friendly strategy performance effects is context specific and contingent on the general business environment conditions pertaining to munificence, dynamism, and complexity. Our findings provide new insights into the conditions under which eco-friendly product development strategies have beneficial, negligible, and/or detrimental effects for product development effectiveness. Specifically, though we find dynamism to exert no significant moderating effect, the results show that the impact weakens when business conditions are highly complex, but becomes stronger with increasing levels of munificence in the business environment. Further, firms with high versus low eco-friendly product development strategies enjoyed enhancements in product development effectiveness by $15.4 \%$ in highly munificent environments and $16.3 \%$ in low-complexity business conditions.

Third, drawing on the sustainability and product development literature streams, along with exploratory interviews with managers, we investigate the role of managerial and input-based factors - top management commitment, corporate environmental support policies, and environmental performance incentives - in stimulating the deployment of ecofriendly product development strategies. Although some of these factors have been examined at the individual green project level, their importance has been overlooked within the context of firms' eco-friendly product development strategies. Our study provides new evidence of how firms can internally facilitate and support the deployment of eco-friendly product strategies. 


\section{Pertinent literature}

In recent years, researchers have shown increasing interest in examining how environmental sustainability issues can be incorporated into marketing (e.g., Chabowski et al. 2011), management (e.g., Etzion 2007), and operations (e.g., Angell and Klassen 1999). A growing stream of research has focused on the integration of environmental issues into product development and innovation (for reviews see Cronin et al. 2011; Dangelico 2015; Varadarajan 2015). Studies in this stream fall mainly into three areas. The first area centers specifically on green product development practices, discussing their very nature in terms of content (e.g., packaging, life cycle approaches, design), types (e.g., radical, incremental), scope (e.g., strategies, programs, projects), and measurement (e.g., systems, frameworks, tools) (e.g., Dangelico and Pujari 2010; Matos and Hall 2007; Melnyk et al. 2003). However, while the literature provides various definitions of sustainable product development and/or innovation, some of these exhibit important limitations in terms of scope, clarity, and domain (see Varadarajan 2015), and operationalizations differ considerably from one study to another. This inhibits comparability and generalizability of findings, cumulative knowledge development, and disciplinary maturity.

The second focuses on the performance effects of ecofriendly strategies. Over the last two decades, many studies have been conducted on the organizational performance outcomes of corporate responsibility and sustainability. However, studies provide mixed and contradictory results, triggering a heated debate about the value of corporate responsibility and sustainability practices. Some scholars (i.e., Golicic and Smith 2013; Orlitzky et al. 2003) have tried to resolve the issue by following a meta-analytical approach. Orlitzky et al.'s (2003) meta-analysis identifies 52 studies on the performance implications of social and environmental practices and reveals a generally positive effect of such practices on the performance of the firm. Similarly, a more recent meta-analytic effort (i.e., Golicic and Smith 2013), based on 159 sustainability articles examining performance outcomes, shows strong positive effects of environmental design and production practices on market-, operational-, and accounting-based performance.

Notwithstanding these findings, less empirical attention is given to the study of product development outcomes of green product strategies. Our review of the literature (see Table 1) reveals that most studies in this area focus on manufacturing firms in certain countries such as the U.S., Taiwan, and China; only one study (i.e., Pujari et al. 2003) investigates this relationship in a U.K. context. Further, most studies use the firm as the unit of analysis. Only four studies center on the project level (e.g., Chen and Chang 2013), one of which is a qualitative study (i.e., Galeazzo et al. 2014). Finally, cross-sectional research designs have traditionally been used, making it difficult to establish causality.
In this area, research has examined a variety of aspects, including environmental new product development, green product innovation, and eco-design. Scholars (e.g., Mitra and Datta 2014) have studied these aspects together with other eco-friendly practices (e.g., environmentally sustainable logistics). Most studies assess product development performance using multiple indicators (e.g., Sroufe 2003) and consider outcomes along with other performance aspects, such as return on investment, corporate image, and profitability (e.g., Chang 2011). Some studies focus on green project or product development performance (e.g., Chen and Chang 2013; Pujari 2006). Importantly, research in this area reports mixed results and pays little attention to contextual factors potentially influencing the effects of such practices. These inconsistencies in empirical findings and conceptual shortcomings hint at the need to identify factors that enhance or inhibit relationships of eco-friendly product development to effectiveness outcomes.

The third area concerns studies examining drivers of ecofriendly product development. For example, Sharma and Henriques (2005) focus on the role of stakeholder influences in affecting sustainability practices, and Sarkis et al. (2010) find that stakeholder pressures have an indirect impact on ecodesign through environmental training. Driessen and Hillebrand (2013) distinguish between market and nonmarket stakeholders, highlighting the role of stakeholder integration capability in managing tensions between the two. Dangelico and Pujari (2010) identify the need for regulatory compliance, opportunity of enhanced competitiveness, and value- and ethically driven factors as the key drivers of green product innovation. Pujari et al. (2004) highlight the significance of a functional interface between environmental specialists and product development teams, top management support, and explicit environmental policies in fostering green new product activities. Similarly, Zhu et al. (2008) find a positive link between managerial support and organizational learning with eco-design. Finally, Chen and Chang (2013) and Dangelico et al. (2013) focus on how specific firm capabilities can stimulate green product design and creativity. This examination of the literature reveals a focus on a set of ecofriendly product development activities at the project level of analysis, an emphasis on external drivers of eco-friendly product development, and a lacuna of knowledge on how firms integrate environmental issues in product development.

\section{Theoretical framework and hypotheses}

Our study falls into the domain of resource-based view (RBV) research in marketing, which postulates that a firm's performance outcomes are largely driven by its resources and capabilities (for thorough review see Kozlenkova et al. 2014). Within this broad domain of RBV, we draw on Lado et al. (1992) and Lado and Wilson's (1994) model of competitive 


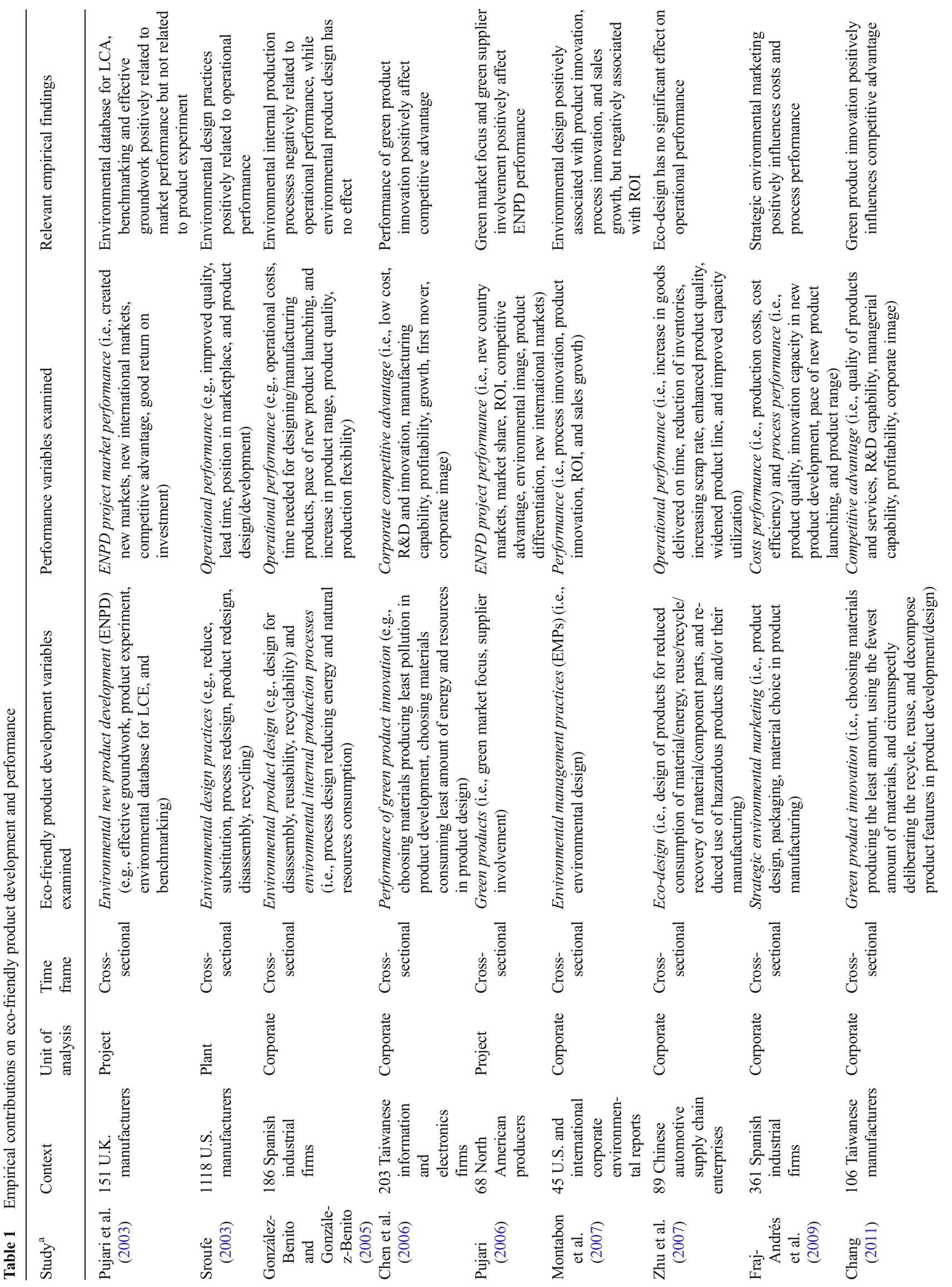




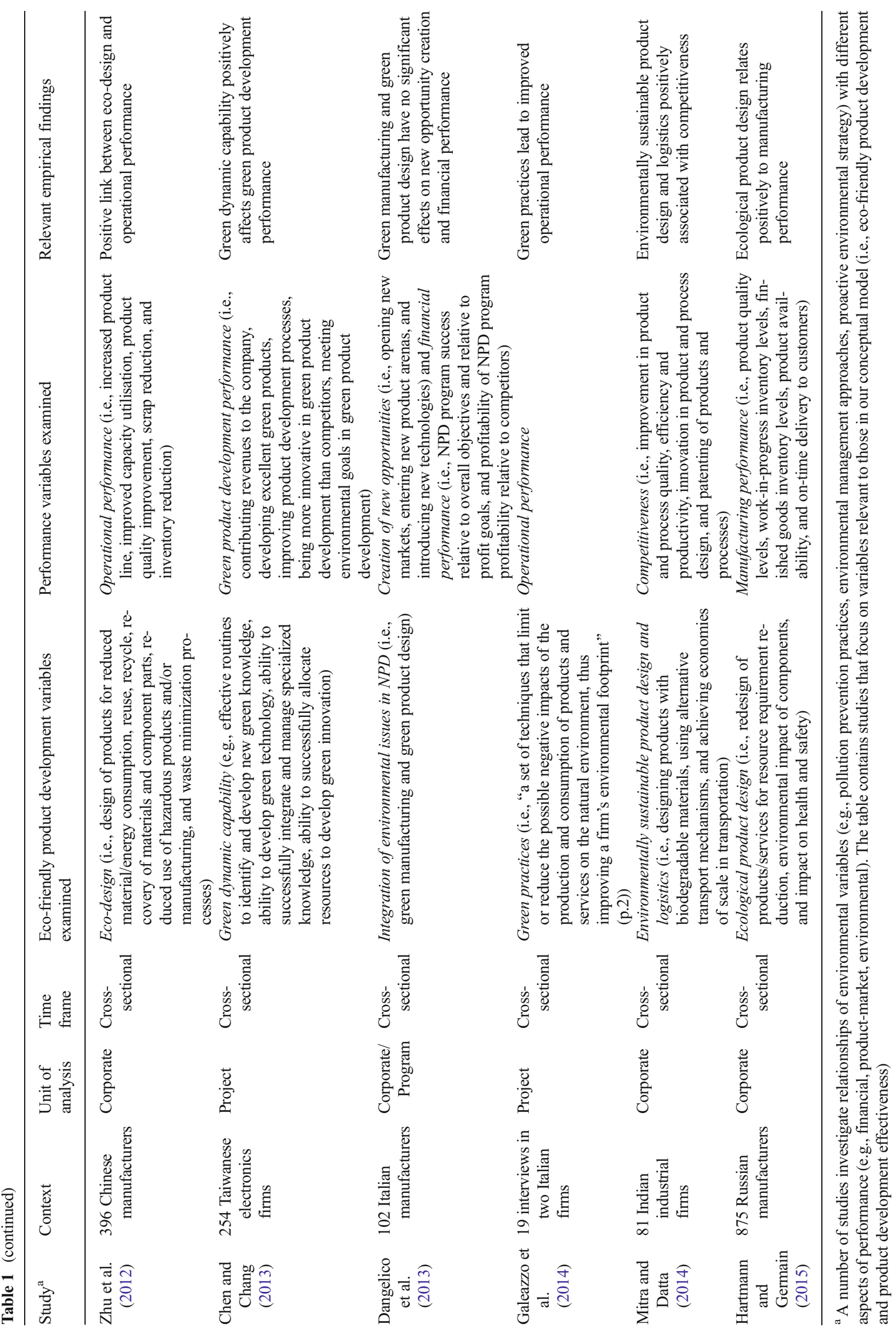


advantage as the thread that ties together all main-effect hypotheses (and constructs) and also use contingency theory to conceptualize the business environment's role in moderating the effectiveness outcomes of eco-friendly product development strategies (see Fig. 1). This model distinguishes among four types of firm resources and capabilities: managerial, unique knowledge and skills of corporate leaders to articulate and communicate a strategic vision and strike a balance between the organization and its environment; input-based, resources, knowledge, and skills that enable a firm's transformational processes to create and deliver valuable goods and services to customers; transformational, organizational processes (e.g., innovation, learning) that help a firm convert inputs into outputs; and output-based, the physical and invisible outputs the firm might put together to offer value to customers.

We contend that a firm's advantage position from ecofriendly product development strategies depends on the configurations of specialized resources available in the firm. These are synergistically combined, transformed, and then channelled into key organizational processes and activities. Such valuable configurations are reflected in managerial and input-based resources that constitute integral sources of transformational capabilities, which ultimately lead to enhanced performance outcomes (Lado et al. 1992). Transformational capabilities (i.e., eco-friendly product development strategy) are the outcome of interactive deployment of input resources (i.e., corporate environmental support policies and incentives) needed to create an enacting organizational environment that is based on managerial support (i.e., top management commitment) (Lado and Wilson 1994).
Our focus on eco-friendly product development strategy is grounded on the natural resource-based view (NRBV) (see Hart 1995), an extension of the RBV of the firm (Barney 1991). With growing physical constraints imposed by the natural environment, escalating stakeholder demands for greater sustainability, and the increasing importance of ecological problems for organizations, Hart (1995) contends that strategy and performance must be rooted in capabilities that facilitate environmentally sustainable economic activity. Marketing scholars (e.g., Day 1994) argue that in today's environment, firms need capabilities that have both an "inside-out" and a matching "outside-in" perspective to sense and exploit external possibilities that matter. In line with this thinking, Day (2011) stresses the importance for market-driven firms to develop adaptive marketing capabilities that enable the anticipation of trends and faster adjustments to key changes in the market.

Following this logic, scholars (e.g., Aragon-Correa and Sharma 2003) have conceptualized proactive environmental strategies as capabilities that can help firms achieve a strong market position and enhanced performance results. These strategies help anticipate market changes and demand for sustainable products and equip the firm with the necessary skills and knowledge to respond effectively. Accordingly, we view eco-friendly product development strategy as a transformational market-based capability that reflects decisions, actions, and changes in the design, development, and finalization of products geared toward protecting or benefiting the natural environment (Dangelico et al. 2013). Eco-friendly product development strategies are proactive in nature and enable the

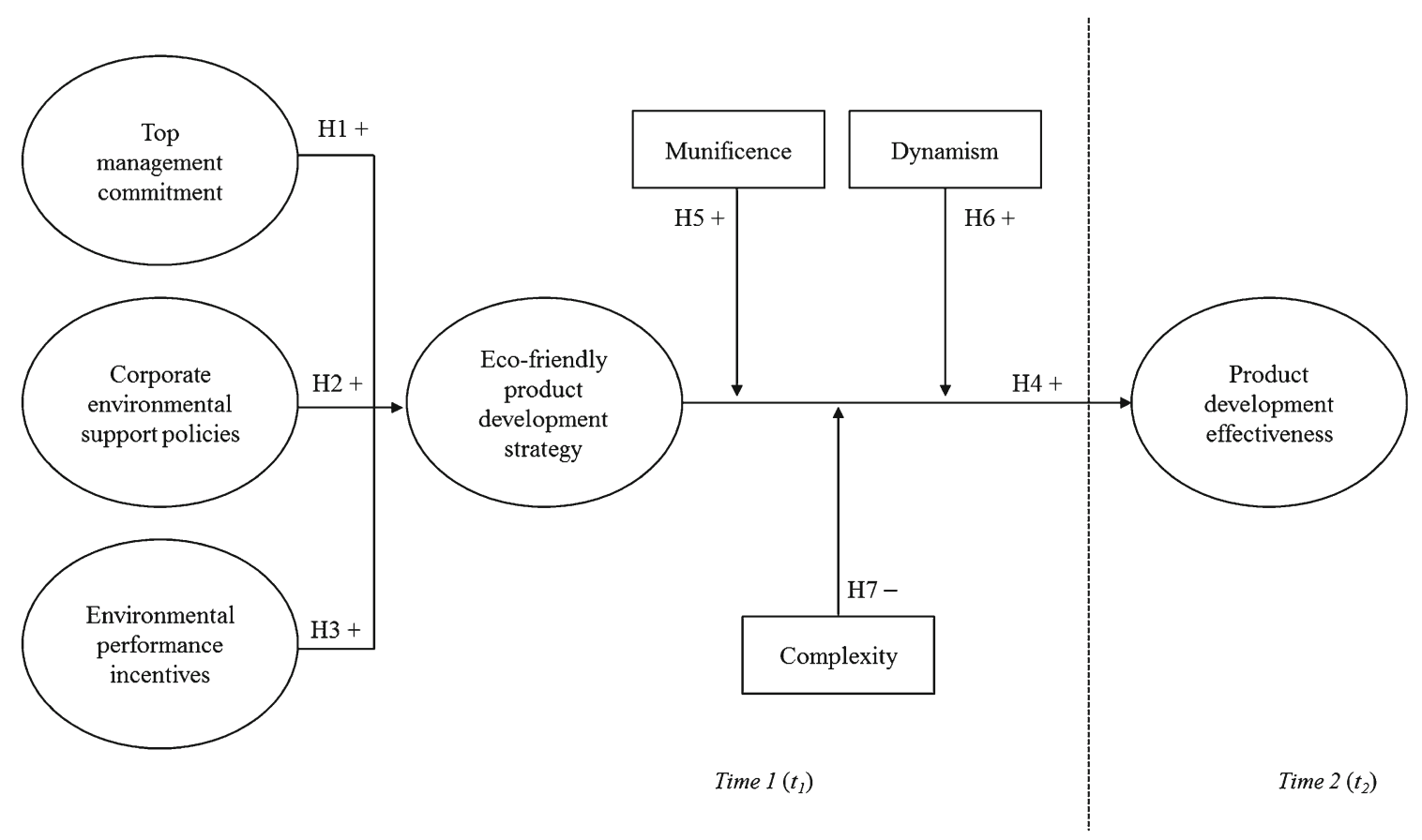

Fig. 1 Conceptual model 
firm to make sense of and adapt quickly to increasingly volatile markets. They focus on friendly to the environment practices (e.g., energy conservation, waste and pollution minimization, efficient resource utilization) aiming to improve the environmental impact of products at different lifecycle stages (i.e., design, manufacturing, usage, and disposal) (Dangelico and Pujari 2010).

This type of eco-friendly product development capability enables the firm to convert inputs into outputs (Lado et al. 1992). It corresponds to product stewardship strategy in Hart's (1995) NRBV, as it involves eco-friendly activities throughout the value chain and the integration of ecological factors in product design and development routines (Hart and Dowell 2011). From this perspective, we suggest eco-friendly product development strategies are idiosyncratic in nature because of (1) their social complexity, involving combinations of resources from various organizational units; (2) their proactive nature, which requires sufficient managerial initiative and discretion to reconfigure resources; and (3) the specific technical expertise needed to introduce and manage new technologies and processes (Boiral 2002). Further, eco-friendly product development strategies touch on Day's (2011) adaptive marketing capabilities and, particularly, on the adaptive market experimentation concept. Such market-driven strategies enable the firm to explore new initiatives and ideas, share insights and successful practices internally, and work with partners to learn from experience.

Eco-friendly product development strategies involve tacit, complex, and causally ambiguous routines (e.g., lifecycle approaches, design-for-the environment schemes) and are firm specific, path dependent, inimitable, rare, and not easily substitutable (Aragon-Correa and Sharma 2003). In addition, such strategies can create value for the firm and its customers through enhanced innovation (e.g., new eco-friendly products), entrepreneurial orientation (e.g., pursuit of new environmental market opportunities), corporate reputation (e.g., distinct from competition), and technological sophistication (e.g., adoption of green technologies) (Menguc et al. 2010; Porter and van der Linde 1995). Eco-friendly product development strategies can also lead to cost reduction through more efficient use of processes, resources, and inputs (Aragon-Correa and Sharma 2003) across different product development projects.

We posit that the effects of a market-based transformative capability, such as an eco-friendly product development strategy, can vary depending on different characteristics of the business environment that enable the firm to continuously adapt to dominant conditions (Aragon-Correa and Sharma 2003; Day 2011). Managers usually perceive exogenous business environment factors as threats or opportunities (Sharma 2000). Taking insights from contingency theory (e.g., Lawrence and Lorsch 1967), we thus argue that an environmental strategy's value-enhancing effects depend on managerial perceptions of the prevailing conditions in the general business environment of the firm.

\section{Top management commitment}

Top management commitment is the extent of senior-level managerial commitment, support, and leadership in the pursuit of corporate environmental preservation and deployment of corporate environmental practices. Commitment at the top level is a managerial resource that is vitally important to the deployment of an eco-friendly product development strategy (e.g., Berry and Rondinelli 1998). It demonstrates the importance of environmental sustainability for the firm's operations and the need to acquire and accumulate knowledge based on lessons from past organizational experiences (e.g., Kleinschmidt et al. 2007). Such commitment enables top managers to communicate with and empower employees to realize the firm's strategic environmental aspirations and also helps firms build other important capabilities (Gavronski et al. 2011; Wittmann et al. 2009).

In line with this thinking, Hart (1995) argues that corporate vision and strong leadership are key facilitators for developing environmental capabilities. This is because employees are generally more motivated when they perceive support from managers at higher levels (Ramus and Steger 2000), and strong leaders passionate about and committed to environmental protection can inspire employees to embrace a green corporate ethic (Menguc et al. 2010). Top management commitment can also provide a clear vision of the required strategy, create enthusiasm among workforce (González and Palacios 2002), and enable the allocation of company resources to developing eco-friendly product development routines and capabilities (Pujari et al. 2003). In addition, strong top management commitment to greater environmental sustainability can facilitate coordination of environmental activities (Pujari and Wright 1996) and send a strong message to employees about the importance of environmental concerns (Banerjee et al. 2003).

Empirically, top management commitment was found to influence environmental corporate and marketing strategies (Banerjee et al. 2003), green supply chain practices (Zhu et al. 2008), and eco-performance of environmental new product development (Pujari et al. 2003). Therefore, we expect that top management commitment will be conducive to the deployment of an eco-friendly product development strategy. Thus:

H1: Top management commitment to environmental preservation has a positive effect on the extent to which the firm deploys an eco-friendly product development strategy. 


\section{Corporate environmental support policies}

Corporate environmental support policies refer to the presence of departments, personnel, systems, and/or procedures to support the management of environmental issues in the firm (Menon and Menon 1997). For example, organizations develop policies to support green initiatives through the recruitment of individuals with expert knowledge (e.g., environmental manager, sustainability champions), the provision of specialized training programs on implementing environmental procedures, the integration of formal environmental systems (e.g., Total Quality Environmental Management, Environmental Management Systems), and the use of environmental elements in decision making and communication processes. Firms require organizational processes and knowledge-sharing routines to encourage people to perform specific productive activities (e.g., Lockett and Wright 2005). The literature points to the importance of installing environmental support polices in the firm to facilitate effective product development practices. For example, Pujari et al. (2003) reported positive effects of environmental coordinators on eco-performance, while Pujari et al. (2004) found that an explicit green policy is conducive to the adoption of environmental lifecycle activities.

Environmental support policies can help product development employees understand the required tasks and how to perform key processes and routines effectively (e.g., Kleinschmidt et al. 2007). Specifically, specialized environmental departments, along with the existence of formalized environmental procedures, can be instrumental in helping firms respond swiftly to stakeholder environmental demands, provide cutting-edge information on environmental best practices, and communicate green achievements and changes to interested parties (Menon and Menon 1997; Sarkis et al. 2010). Environmental support policies enable employees at all levels to consider standards, goals, and targets in managing individual and organizational environmental performance (Berry and Rondinelli 1998) and may also send a strong message throughout the firm about the need to develop skills in environmental product development (Ramus and Steger 2000). In addition, such policies can help firms (1) boost employee creativity to come up with innovative solutions to environmental problems (Ramus 2001) and (2) provide the necessary skills, expertise, and knowledge among workforce to develop path-breaking strategic environmental capabilities (Branzei et al. 2004; Renwick et al. 2013). As a result, firms with strong environmental support policies can more effectively integrate environmental aspects in product development and deploy eco-friendly product development strategies. Thus:
H2: Corporate environmental support policy has a positive effect on the extent to which the firm deploys an ecofriendly product development strategy.

\section{Environmental performance incentives}

The literature recognizes that organizational processes and routines are key resources within the firm (Barney 1991). Firms require routines related to incentives and rewards to encourage employees to perform important organizational activities (Lockett and Wright 2005). This is of particular relevance to product development, because evidence shows that the best way to facilitate innovation in a firm is to develop reward and punishment schemes linked to organizational structures and decision making (Sarin and Mahajan 2001). We argue that environmental performance incentives are important input-based resource mechanisms that link individual employee performance with eco-friendly product development strategies.

Such reward systems are part of an organization's processes and help employees engage in knowledge-sharing routines, increase information absorption, and evaluate and transmit skills within the firm (Mahoney 1995). First, these incentives can be instrumental in helping employees better understand sustainability problems and targets (Hart 1995) and motivating them to embrace green initiatives on a more competitive basis (Govindarajulu and Daily 2004). Second, these incentives can work as managerial signals that affect employees' willingness to support and promote eco-initiatives within the firm (Ramus and Steger 2000). One the one hand, line managers get a signal that their firm is committed to environmental product development with the provision of tangible financial resources for distribution (Ramus 2001). On the other hand, employees enjoy recognitions and rewards when specific environmental targets and companywide goals are achieved. As a result, employees learn to operate in an environment with more open communication which encourages them to constantly think of new eco-initiatives, but, at the same time, unrestrainedly discuss their environmental ideas with superiors and co-workers (Ramus 2001). Thus, a sound environmental reward system can drive employees to embed ecological elements in product development strategies, develop environmental innovations in the workplace, and generate distinctive green-related capabilities (Paillé et al. 2014).

Firms can use many types of incentives to reward employees for good environmental practices, including pay raises, promotions, recognition awards, and position performance appraisals (Daily and Huang 2001). For example, various schemes have been introduced in the U.K. such as the "carbon credit" and "green benefit" cards, specific cash incentive plans for staff meeting environmental targets, and 
annual gala award events that recognize exemplary environmental performance (Renwick et al. 2013). However, to be impactful, these rewards and incentives must be realistic and effective, and also reflect the firm's sensitivity and commitment to environmental issues (Hunt and Auster 1990). In this way, employees are more empowered in decision making, motivated to come up with product solutions that enhance environmental performance, and receptive to managerial messages of the firm's direction in eco-friendly product development. Thus:

H3: Environmental performance incentives have a positive effect on the extent to which the firm deploys an ecofriendly product development strategy.

\section{Eco-friendly product development strategy and product development effectiveness}

Research suggests that the process of greening can help organizations gain valuable experiential knowledge of new practices and master new technologies (Boiral 2002). Developing environmental knowledge enables firms to find ways of maximizing efficiencies and exploring new market opportunities. Experiential knowledge gained from involvement in ecofriendly operations flows from one department to another in the firm (Ambec and Lanoie 2008). This flow facilitates an innovative firm culture, potentially increasing new product introductions (Nidumolu et al. 2009). Thus, green practices are critical for enhancing and rejuvenating a firm's product development activities (Hopkins 2010).

We argue that an eco-friendly product development strategy has positive product development effectiveness outcomes. Product development effectiveness refers to how well the firm manages its product development processes by offering new products and improving existing ones to effectively satisfy customers. Scholars suggest embracing sustainability can be beneficial for firms in terms of new product sales, employee commitment, and customer satisfaction and retention (e.g., Menon and Menon 1997). Sustainability practices can also improve financial performance as a result of "market gains" and "cost savings" in the firm's operations (Klassen and McLaughlin 1996). As Porter and van der Linde (1995, p. $125)$ note, "innovating to meet regulations can bring offsets: using inputs better, creating better products, or improving product yields." Organizations proactively engaging in environmental marketing and management may thus increase their innovation activities, productivity, and competitiveness. Arguably, firms involved in eco-friendly product development are in a better position to reduce their product cost structures, exploit business opportunities in response to stakeholder sustainability demands, and develop innovative product ideas (Nidumolu et al. 2009).
In addition, efficiencies from eco-friendly product development strategies can spill over to other firm projects related to new product design or existing product improvement (Ambec and Lanoie 2008). They are likely to result in a continuous pattern of improved product introductions in terms of quality, attractiveness, and price, potentially strengthening the firm's competitive position and performance. A typical example is Toyota's experience with the Prius hybrid model. Many green initiatives introduced by the model's development in the late 1990s have contributed to the creation of important ecofriendly knowledge. In turn, the Prius has served as a platform for the development of new commercial models (e.g., Auris hybrid) and upgrades (e.g., third-generation Prius), enabling the company to achieve and sustain product leadership. Procter \& Gamble likewise conducted lifecycle assessments to improve the environmental credentials of its products. A few years ago, the company introduced Tide Coldwater in the United States and Ariel Excel Gel in the United Kingdom, two products with a unique formula for washing clothes in cold temperatures (Nidumolu et al. 2009). Emphasizing lower energy costs and compact packaging, cold-water technologies were subsequently integrated in product line extensions and successful new product innovations (e.g., Ariel Actilift Powder, Tide Pods).

A stream of empirical research has examined the effect of green product development practices on operational, innovation, and product development outcomes. However, these studies report mixed results. For example, Sroufe (2003) finds a positive link between green design practices and operational performance, while Fraj-Andrés et al. (2009) report positive effects of strategic environmental marketing on costs and process performance. In contrast, González-Benito and González-Benito (2005) reveal that green internal production processes and green product design had negative and neutral effects on operational performance, and Zhu et al. (2007) show no significant effects of eco-design on operational performance. Despite the mixed results in the literature, most studies suggest that eco-friendly product development will be beneficial for a firm's product development effectiveness. Hence:

H4: The extent to which the firm deploys an eco-friendly product development strategy has a positive effect on the firm's product development effectiveness.

\section{The contingent role of the business environment}

Contingency theory argues that organizational performance is a function of the proper alignment between endogenous organizational factors (e.g., strategies) and exogenous context variables (i.e., business environment) (e.g., Lawrence and Lorsch 
1967). Therefore, a fit between organizational strategies and dominant forces in the business environment is critical for the success of these strategies. Sustainability researchers have used strategic fit thinking to consider direct (e.g., Russo and Fouts 1997) and moderating (e.g., Aragon-Correa and Sharma 2003) effects of the business environment. Drawing on insights from the theory of strategic fit, we posit that the impact of eco-friendly product development strategy on product development effectiveness is contingent on three key business environment dimensions: munificence, dynamism, and complexity.

Munificence in the business environment Munificence refers to the ability of the business environment to support sustained growth of a firm through the satisfaction of demand, realization of opportunities, and utilization of resources (Achrol and Stern 1988). In high-growth markets, firms are more likely to generate and use slack resources for innovation and exploration of new products and ideas (Menon and Menon 1997; Rueda-Manzanares et al. 2008). This resource availability provides firms with greater opportunities to change routines and expand on successful product ideas (Aragon-Correa and Sharma 2003), potentially enhancing the beneficial effect of cross-fertilization of eco-friendly product ideas and practices on product development activities and success. For example, Russo and Fouts (1997) show that the financial benefits of a firm's environmental performance are higher in industries marked by high growth.

In contrast, lack of munificence may create resource scarcity in the market, pushing firms to adopt a more mechanistic structure based on greater formalization, standardization, and centralization (Yasai-Ardekani 1989). In this context, managers typically respond by discouraging experimentation and creativity in an effort to increase efficiency, tighten control, and cut costs. They also attempt to hold on to their positions in a shrinking market by limiting financial risks and resisting change to more eco-friendly routines. Accordingly, ecofriendly product development capability may have limited flexibility to be translated into product development effectiveness, because managers may be unwilling or unable to deploy resources and nurture new environmentally friendly ideas and innovations. As a result, the use of eco-friendly product development capability is likely to yield lower positive returns for such firms than for firms operating in highly munificent business environments (Russo and Fouts 1997). Thus:

H5: The extent to which the firm deploys an eco-friendly product development strategy has a stronger effect on product development effectiveness when munificence in the business environment is high than when it is low.
Dynamism in the business environment Dynamism refers to the rate of change of market factors in a firm's business environment (Achrol and Stern 1988). Changes in customer preferences, product standards, marketing practices, and technology are key elements of dynamic environments (Sarin and Mahajan 2001). Rapid changes in market factors can pose significant challenges for the firm's operations and performance outcomes. However, when fundamental market forces are relatively stable, organizations tend to be more willing to capitalize on current practices, use existing resources freely, and go with "more of the same" than "more of something different" (Drnevich and Kriauciunas 2011, p. 259). In such conditions, certain organizational capabilities such as ecofriendly product development may become costly and risky to possess, due in part to rivals' intentions to conform and adopt such capabilities (Schreyögg and Kliesch-Eberl 2007). Thus, when capability in eco-friendly product development becomes common practice among firms in stable environments, the focal firm's competitive superiority over rivals decreases and its performance suffers.

In contrast, we expect the positive effect of eco-friendly product development strategy on eco-friendly product development effectiveness to increase in more dynamic business environments. This is because firms need to enhance understanding of customer preferences and purchasing behavior, constantly seek new opportunities, and be adaptable to changing customer requirements (Achrol and Etzel 2003). Thus, dynamism creates opportunities for firms to enact the type of radical changes needed and focus on innovations that could improve their marketplace position (Baron and Tang 2011). Such opportunities can involve sustainability-related modifications and innovations (Rueda-Manzanares et al. 2008) and help proactive environmental firms achieve greater efficiencies, develop higher-quality products, and boost their product development outcomes. As a transformational capability, ecofriendly product development strategy can play a fundamental role in changing other organizational routines and ensuring that firms can adequately alter their overall operations to better adjust to new market conditions (Drnevich and Kriauciunas 2011). It can also help firms create novel problem-solving patterns and perform frequent and complex changes in innovation routines that bring about regular modifications of established operating practices (Schreyögg and KlieschEberl 2007). Thus:

H6: The extent to which the firm deploys an eco-friendly product development strategy has a stronger effect on product development effectiveness when dynamism in the business environment is high than when it is low.

Complexity in the business environment Complexity reflects the diversity and multiplicity of factors in the business 
environment in which the firm operates (Smart and Vertinsky 1984). The greater the number of factors that affect the firm's operations and the larger the differences among them, the more complex the business environment is. Managers perceive complex environments as more uncertain and believe that more information processing is needed in such contexts (Aragon-Correa and Sharma 2003). Scholars (e.g., Tang et al. 2015) suggest that complexity in the business environment may inhibit an organization's ability to develop successful new product offerings. This is because managers pay greater attention to monitoring unpredictable trajectories and complexities in the market and spend more time interacting with multiple and often conflicting stakeholders. Such distraction shifts managerial attention away from key areas such as innovation.

Furthermore, complex business environments usually increase competition, reduce the availability of resources and opportunities, decrease profit margins, and limit strategic options for firms (Miller and Friesen 1983). Changing product development operations in complex environments is difficult because firms rely more on limited adjustments to existing practices (Aragon-Correa and Sharma 2003). Thus, managers are more reluctant to take successful environmental product development initiatives on board and might prefer a less resource-demanding approach to enhancing product development operations (Rueda-Manzanares et al. 2008). In contrast, when complexity in the business environment is low, managers are better able to recognize the value of sustainability initiatives, have more time to devote to the development of environmental ideas, and are more willing to take advantage of the greater availability of resources. As such, they will be in a better position to use eco-friendly ideas in product development projects that enhance the firm's effectiveness. In line with this, we posit that complexity has a negative moderating effect on the eco-friendly product development strategy-product development effectiveness link. Thus:

H7: The extent to which the firm deploys an eco-friendly product development strategy has a weaker effect on product development effectiveness when complexity in the business environment is high than when it is low.

\section{Research methodology}

\section{Research context}

The empirical context for this study is U.K. manufacturing firms' eco-friendly product development practices. We used a multi-industry sample, covering food, paper products, chemicals, rubber, plastics, metal, and transportation equipment, to secure a size large enough to allow rigorous data analysis and enhance generalizability. To test the links and effects of interest in the study, we focused on single business-dominant firms. When considering performance outcomes, the choice of such firms helps reduce the potential problem of differences between corporate- and businesslevel practices (e.g., eco-friendly strategies) and minimize possible extraneous influences (Yarbrough et al. 2011).

\section{Field interviews}

We initially conducted in-depth interviews with 14 top managers to deepen understanding of the topic, enrich our conceptual model, and ensure the meaningfulness of our constructs. These managers were CEOs, managing directors, or senior executives in areas such as marketing, operations, and $\mathrm{R} \& \mathrm{D}$ /product development. We included firms of different sizes and from a cross-section of industries exhibiting dissimilar levels of environmental performance. Interviews lasted between 60 and $90 \mathrm{~min}$ and began with general questions about the role of environmental issues in the firm, followed by more specific questions related to the conceptual model and its focal constructs.

The interviews verified the plausibility of the model and confirmed that environmental issues are gaining importance in organizations as pressure from various external stakeholders mounts. Given the technical nature of sustainability issues, managers perceived the presence of environmental support policies (e.g., specialists, training, and systems) and collaboration across organizational units as essential for integrating sustainability elements in product development. Managers also highlighted the important role of top management in gauging a response from company departments and employees to address sustainability issues (e.g., verbal support, written statements, provision of incentives). Importantly, environmental ideas and knowledge seem to be disseminated within the organization and integrated in other product development projects. However, interviewees perceived that the cross-fertilization of environmental ideas within the firm, application of eco-friendly practices to new product development projects, and effectiveness outcomes of such practices take time to unfold, which suggested the need for a time lag in our study.

\section{Measures}

Following a systematic review of the literature, complemented with insights from our field interviews, we identified multiitem measures for operationalizing the study constructs. These were subsequently adapted to the study context. We also included several control variables to avoid model misspecification. Specifically, we used regulatory, customer, 
and competitive pressures for corporate greening because pressures from various external stakeholders may affect the firm's decision to engage in eco-friendly product development (e.g., Sarkis et al. 2010). In addition, we controlled for crossfunctional coordination given the importance of for ecofriendly product development and product development effectiveness (e.g., Pujari et al. 2003). Finally, in line with prior research (e.g., Dangelico et al. 2013), we controlled for the effect of firm size, using a log transformation of the number of employees. Table 2 provides the complete list of items and anchors of the scales as well as their sources.

To ensure face validity, we employed five academics familiar with research on sustainability marketing and product development as expert judges. We asked them to assess whether the measures matched the theoretical definitions and to evaluate the extent to which each scale item was representative of the particular construct in question. Following a series of modifications and refinements, the judges reached consensus: all items were rated as "highly representative" or "somewhat representative" of their given constructs, and no item was regarded as "not at all representative." We then developed a draft questionnaire that we further refined in personal interviews with six senior executives. Next, a formal mail pretest took place using a sample of 65 firms that were excluded from the main survey. We received 21 completed responses, which revealed no particular problems with the questionnaire.

\section{Sample and data collection}

We randomly selected 1000 manufacturing firms from Dun \& Bradstreet's Key British Enterprises (KBE) directory for the study. Each firm was initially contacted by telephone to verify contact details and eliminate potential duplication of firms in the database. As a result, 188 firms were dropped because of duplication of entries (98 firms), incorrect contact information (49 firms), and discontinuation of operations (41 firms). All remaining firms were subsequently contacted to identify appropriate key informants and request their participation. Key informants had to be senior managers who were key decision makers in their firms, knowledgeable of their firm's activities, and were both able and willing to provide the necessary information. After consecutive calls, we identified 517 managers in corresponding firms who met the study eligibility criteria. In total, we excluded 295 firms: 71 because no appropriate informants were located, 33 because key informants could not be reached, 59 that were unwilling to participate, 57 that were reluctant to disclose potential informants, 49 that had policy restrictions for external survey participation, and 26 that reported that the topic was not applicable to their business (i.e., absence of product development or R\&D activities).

To test our hypotheses, we collected data at two points in time (e.g., De Ruyter et al. 2009). Specifically, we gathered responses on top management commitment, corporate environmental support policies and incentives, the business environment (i.e., munificence, dynamism, and complexity), and eco-friendly product development strategy at $t_{l}$ and data on effectiveness outcomes at $t_{2}, 1$ year later. We mailed a survey packet containing information about the study, the questionnaire, and a postage-paid return envelope to each of the 517 key informants. We used university stationery and offered a report of the results and the possibility of winning a prize in a draw as incentives to participate. Reminder postcards, two additional waves of questionnaires, and telephone reminders produced 234 responses. Of these, 13 questionnaires were dropped because of failure to meet our post hoc informant requirements (see next subsection). Thus, the usable questionnaires at $t_{1}$ were 221 , yielding a response rate of $42.7 \%$ (i.e., 221/517). ${ }^{2}$

The literature provides little theoretical rationale for the use of an appropriate time interval that allows green spillover effects to materialize and thus enables assessment of eco-friendly product development outcomes. Thus, we selected a 1-year temporal interval for this study, a choice guided by our field interviews. Specifically, some managers experienced limited change in product development effectiveness during the last year, but the majority reported considerable change in terms of improving or deteriorating product development outcomes. This choice is also consistent with common research practice in marketing (e.g., Mena and Chabowski 2015). Thus, 1 year later $\left(t_{2}\right)$, we contacted the respondents again and asked them to provide data on product development effectiveness by completing a short follow-up questionnaire. Of the 221 participants at $t_{1}, 185$ completed this questionnaire at $t_{2}$. Two questionnaires were dropped because they failed the informant quality test. Thus, the response rate for the $t_{2}$ sample was $82.8 \%$ (i.e., 183/221). The final sample for testing the hypotheses comprised 183 responses containing data collected at two points in time, representing an overall effective response rate of $35.4 \%$ (i.e., $183 / 517$ ).

Informant evaluation We included three questions at the end of the questionnaire to assess, on a seven-point scale $(1=$ very low, $7=$ very high), key informants' knowledge, competence, and familiarity with the issues studied. We eliminated $15 t_{1}$ and $t_{2}$ responses that exhibited a score lower than 4 on any of these items. The mean composite ratings for informant quality in the sample $(n=183)$ were 5.87 at $t_{1}$ and 6.02 at $t_{2}$, providing confidence in the competence of our key informants. We also managed to collect data from a second informant in 22 and 17 of the participant firms at $t_{1}$ and $t_{2}$, respectively. Correlations between the responses of the two raters were high and significant ranging from $0.78(p<0.01)$ to $0.91(p<0.01)$, offering additional evidence of the quality of our key informant data.

\footnotetext{
${ }^{2}$ The response rate for $t_{l}$ was $32.0 \%(234 / 730.8)$ based on Wiseman and Billington's (1984) more conservative formula for calculating response rates.
} 
Table 2 Measurement and loadings for survey items

TMC - Top management commitment ${ }^{\mathrm{b}}$ (Adapted from Banerjee et al. 2003)

TMC1 - The top management team in our organization is committed to environmental preservation.

$0.86^{\mathrm{c}}$

TMC2 - Our top management team provides full support to our organization's environmental efforts.

$0.88(16.14)$

TMC3 - The top management team in our organization drives through its commitment the organization's environmental efforts.

$0.93(17.98)$

TMC4 - The top management team in our organization is highly interested in catering for the needs of customers who are

$0.75(12.38)$ environmentally conscious.

TMC5 - The top management team in our organization is geared toward providing environmentally friendly products.

CESP - Corporate environmental support policies ${ }^{\mathrm{b}}$ (Adapted from Langerak et al. 1998 and Pujari et al. 2003)

CESP1 - We have a specialized person or department responsible for coordinating environment-related issues.

$0.79^{\mathrm{c}}$

CESP2 - We pay particular attention to environmental matters when we communicate things to people inside and outside the organization.

CESP3 - We provide specialized environmental training and education programs to employees.

$0.83(12.35)$

$0.87(13.04)$

CESP4 - We have a formalized environmental caretaking system.

$0.82(12.23)$

CESP5 - We highly appreciate the importance of environmental issues in managerial decision-making.

$0.86(12.94)$

EPI - Environmental performance incentives ${ }^{\mathrm{b}}$ (Adapted from Jaworski and Kohli 1993)

EPI1 - Formal rewards (e.g., pay rises, promotions) are forthcoming to anyone who consistently develops ideas to improve our organization's environmental performance.

EPI2 - In our organization, an individual's environmental performance has a definite effect on his/her performance appraisal.

$0.72^{\mathrm{c}}$

$0.82(10.51)$

EPI3 - Our organization's environmental safety record influences manager and front line supervisor performance evaluations.

$0.77(9.83)$

EPI4 - No matter which department they are in, people in our organization get recognized for being sensitive to environmental

$0.87(10.96)$ concerns.

EPDS - Eco-friendly product development strategy ${ }^{\mathrm{b}}$ (Adapted from Fraj-Andrés et al. 2009 and Pujari 2006)

EPDS1 - We are careful when choosing the contents, ingredients, and raw materials of our products in order to be environmentally friendly.

EPDS2 - We are geared to designing and developing products that are friendly to the environment.

$0.87^{\mathrm{c}}$

$0.84(13.72)$

EPDS3 - We have significantly increased the recycling content of our packaging over the past years.

$0.71(10.78)$

EPDS4 - We use lifecycle analysis to assess the environmental impact of our products.

$0.81(12.28)$

EPDS5 - We tend to modify our packaging and labeling decisions to emphasize any environmental benefits.

$0.73(11.18)$

EPDS6 - We eliminate products from our product line if these are not environmentally friendly. (D)

PDE - Product development effectiveness ${ }^{\mathrm{d}}$ (Adapted from Fraj-Andrés et al. 2009)

PDE1 - Rate of new individual product introductions in the market.

$-$

PDE2 - Rate of launching new diversified products.

$0.89^{\mathrm{c}}$

PDE3 - New individual products' success rate.

$0.88(17.47)$

$0.85(16.25)$

PDE4 - Rate of individual product development extension.

$0.93(19.83)$

PDE5 - Rate of individual product quality improvement.

$0.84(15.77)$

MUN - Munificence ${ }^{\mathrm{b}}$ (Adapted from Achrol and Etzel 2003)

$0.72^{\mathrm{c}}$

MUN1 - The market is characterized by a high rate of economic growth.

$0.84(9.24)$

MUN2 - There is an excellent potential of business in general in the market in which our organization operates.

$0.76(8.97)$

DYN - Dynamism ${ }^{\mathrm{b}}$ (Adapted from Sarin and Mahajan 2001)

DYN1 - In our kind of business, marketing strategies change very frequently.

$0.80^{\mathrm{c}}$

DYN2 - In our kind of business, product standards change very frequently.

$0.85(12.70)$

DYN3 - In our kind of business, customer preferences in product features change very frequently.

$0.85(12.62)$

DYN4 - In our kind of business, technology employed changes very frequently.

$0.76(11.06)$

COM - Complexity ${ }^{\mathrm{b}}$ (Adapted from Low and Mohr 2001)

COM1 - The environment in which our organization operates is ambiguous.

$0.73^{\mathrm{c}}$

COM2 - The environment in which our organization operates is easy. (R)

$0.70(8.24)$

COM3 - The environment in which our organization operates is complicated.

$E R P-E c o-f r i e n d l y$ regulatory pressures $^{\mathrm{b}}$ (Adapted from Banerjee et al. 2003)

ERP1 - Regulation by government agencies has greatly influenced our organization's concern for environmental issues.

$0.91^{\mathrm{c}}$ 
Table 2 (continued)

ERP2 - Environmental legislation can affect the continuing growth of our organization. (D)

ERP3 - Stricter environmental regulation is a major reason why our organization is concerned about its impact on the natural environment.

ERP4 - Our organization's environmental efforts can help shape future environmental legislation in our industry.

$.70(9.98)$

ERP5 - Our industry is faced with strict environmental regulation.

$0.60(8.38)$

$0.65(9.09)$

ECOP - Eco-friendly competitive pressures ${ }^{\mathrm{b} \text { e }}$ (Adapted from Banerjee et al. 2003)

ECOP1 - Competition centering on environmentally-friendly issues is growing in our industry.

$0.98^{\mathrm{c}}$

ECUP - Eco-friendly customer pressures ${ }^{\mathrm{b}}$ (Adapted from Banerjee et al. 2003)

ECUP1 - Our customers feel that environmental protection is a critically important issue facing the world today. $0.71^{\mathrm{c}}$

ECUP2 - Our customers are increasingly demanding environmentally friendly products and services.

$0.80(9.28)$

ECUP3 - Our customers expect our organization to be ecologically friendly.

$0.76(8.99)$

CFC-Cross-functional coordination ${ }^{\mathrm{b}}$ (Adapted from Jaworski and Kohli 1993)

$\mathrm{CFC} 1$ - It is easy to talk to virtually anyone you need to in this organization, regardless of rank or position.

$0.75^{\mathrm{c}}$

CFC2 - There is plenty of opportunity for informal "hall talk" among individuals from different departments.

CFC3 - Employees from different departments feel comfortable about calling each other when the need arises.

CFC4 - Managers discourage employees from discussing work-related matters with those who are not their immediate superiors or subordinates. (R) (D)

CFC5 - People in one department are quite accessible to those in other departments.

CFC6 - Junior managers in this department can easily schedule meetings with junior managers in other departments. (D)

Fit statistics:

$\chi_{(880)}^{2}=1432, p<0.001 ; \chi^{2} / \mathrm{df}=1.63 ; \mathrm{NFI}=0.90 ; \mathrm{NNFI}=0.95 ; \mathrm{CFI}=0.96 ; \mathrm{SRMR}=0.061 ; \mathrm{RMSEA}=0.059 ; \mathrm{AOASR}=0.049$.

${ }^{\mathrm{a}} \mathrm{t}$-values from the unstandardized solution are in parentheses. ${ }^{\mathrm{b}}$ Based on a seven-point Likert scale, where $1=$ strongly disagree and $7=$ strongly agree.

${ }^{\mathrm{c}}$ Item fixed to set the scale. ${ }^{\mathrm{d}}$ Based on a seven-point Likert scale, where $1=$ not at all satisfied, $7=$ very satisfied. ${ }^{\mathrm{e}}$ The error term was set at .10

(R) indicates that the item was reverse scored; (D) indicates that the item was dropped as a result of scale purification

Objective data for validation purposes To validate the effectiveness measure of our study, we identified $t_{2}$ objective data on the number of new product introductions for 28 of our sample firms using Product Launch Analytics from the Data monitor Consumer database. Using a median split, we divided these 28 firms into high and low new product introductions groups. To ensure measure comparability, we then performed a $t$-test to compare the values of the first item of our product development effectiveness measure (i.e., PDE1 - "rate of new individual product introductions in the market") between the two groups. The high new product introductions group reported a significantly higher "rate of new individual product introductions in the market" value than the low new product introductions group $(t=2.93, p<0.01)$. Moreover, we contacted the remaining sample firms by telephone in an attempt to solicit information on the number of each firm's new product introductions at $t_{2}$. We managed to collect such data on another 36 companies that we subjected to the same analysis. Likewise, we detected similar differences in the "rate of new individual product introductions in the market" between the two groups $(t=4.62, p<0.01)$. We also found that this item correlated significantly with the data obtained from Product Launch Analytics $(r=0.54, p<0.01)$ and over the telephone $(r=0.73, p<0.01)$. In summary, these results enhance confidence in the validity of the subjective data provided by our key informants concerning the assessment of product development effectiveness.

Non-response bias We first compared early and late respondents at $t_{1}$ and $t_{2}$ with regard to all measures of the model constructs. No significant differences $(p<0.05)$ were revealed between the early quartile $(n=45)$ and late quartile $(n=45)$ respondent groups on all construct measures. For example, the comparison of the two groups revealed nonsignificant results for top management commitment $(t=-0.91, p=0.368)$, eco-friendly product development strategy $(t=1.43, p=0.157)$, and product development effectiveness $(t=0.88, p=0.383)$. Further, we obtained secondary data (i.e., annual sales volume, number of employees, and firm age) from the KBE directory for 41 randomly selected non-responding firms. $T$-test comparisons between respondents at $t_{1}$ and this group of non-respondents again detected no significant differences $(p<0.05)$ in firm demographics. Collectively, the results of both tests show that non-response bias does not pose a concern in this study. 


\section{Analysis and results}

\section{Measure validation procedure}

To assess the internal consistency of the scales, we first conducted item-to-total correlations for each construct in IBM SPSS 19. Following Bearden and Netemeyer (1998), we eliminated items exhibiting values below $0.50(p<0.01)$. Thus, EPDS6 $(r=0.491, p<0.01)$, CFC4 $(r=0.344, p<0.01)$, CFC6 $(r=0.338, p<0.01)$, and ERP2 $(r=0.459, p<0.01)$ were dropped (see Table 2). Next, we subjected the remaining items to confirmatory factor analysis. We estimated a measurement model that contained 46 items corresponding to the 12 study constructs and control variables. Each item was restricted to load on its a priori defined factor, while all factors were allowed to freely correlate. Because the measurement pertaining to the single-item construct (i.e., eco-friendly competitive pressures) is unlikely to be a perfect estimate, we set the error term at 0.10 to impose measurement error on the scale (Anderson and Gerbing 1988). ${ }^{3}$ We employed the maximum likelihood estimation method using EQS 6.2 (Build $105)$ for Windows. The model fit results showed a significant chi-square statistic $\left(\chi_{(880)}^{2}=1432, p<0.001\right)$, due to the sensitivity of this statistic to sample size and model complexity (Hair et al. 2006; Shook et al. 2004). Nonetheless, the other fit indices suggest an acceptable model fit $\left(\chi^{2} / \mathrm{df}=1.63\right.$, normed fit index $[\mathrm{NFI}]=0.90$, non-normed fit index $[\mathrm{NNFI}]=0.95$, comparative fit index $[\mathrm{CFI}]=0.96$, standardized root mean square residual $[\mathrm{SRMR}]=0.061$, root mean square error of approximation $[\mathrm{RMSEA}]=0.059$, and average off-diagonal absolute standardized residual [AOASR] $=0.049$ ) (Hair et al. 2006). The measurement model results appear in Table $2 .^{4}$

\footnotetext{
${ }^{3}$ We also re-estimated the measurement model using the smallest error variance from the original model (i.e., 0.359) as the error term for the single-item indicator (Anderson and Gerbing 1988). This change did not materially affect the overall fit of the new measurement model (e.g., $\chi_{(880)}^{2}=1432, p<0.001 ; \chi^{2} / \mathrm{df}=1.63 ; \mathrm{RMSEA}=0.059 ;$ SRMR $=0.061$ ), and though it produced a somewhat different factor loading for the single-item construct (i.e., standardized loading $=0.92$ vs. 0.98), the pattern of results remained the same.

${ }^{4}$ As a robustness check, we ran three separate CFA models. The first contained the subjective measures for the controls - cross-functional coordination, eco-friendly regulatory pressures, eco-friendly competitive pressures, and eco-friendly customer pressures $\left(\chi_{(49)}^{2}=50, p>0.05 ; \chi^{2} /\right.$ $\mathrm{df}=1.02 ;$ RMSEA $=0.012 ;$ SRMR $=0.052$ ). The second included the drivers of eco-friendly product development strategy - top management commitment, corporate environmental support policies, and environmental performance incentives $\left(\chi_{(74)}^{2}=144, p<0.001 ; \chi^{2} / \mathrm{df}=1.95\right.$; RMSEA $=0.078$; SRMR $=0.061$ ). The third contained eco-friendly product development strategy, product development effectiveness, munificence, dynamism, and complexity $\left(\chi_{(142)}^{2}=257, p<0.001 ; \chi^{2} /\right.$ $\mathrm{df}=1.81$; RMSEA $=0.067$; SRMR $=0.060$ ). These models meet the sample size criterion, exhibit acceptable fit levels, and yield results consistent with those of our main measurement model.
}

Convergent validity was evident as the standardized factor loadings were high and significant, the average variance extracted (AVE) for each construct exceeded the suggested cutoff point of 0.50 , and all composite reliability scores were high (i.e., above 0.70) (Hair et al. 2006). We assessed discriminant validity using two approaches. First, we used a chi-square difference test for all pairs of constructs (Anderson and Gerbing 1988). We estimated two models in each case: (1) a freely estimated covariance model and (2) a model in which the covariance was constrained to unity. In all cases, the freely estimated model produced a better fit, and the chi-square difference was always statistically significant. Second, we used Fornell and Larcker's (1981) test and found that for all pairs of constructs, the squared correlation was lower than the AVE estimates. Collectively, the results of both tests indicate discriminant validity among the constructs. In sum, the scales employed have adequate measurement properties and thus can be used to test the hypotheses. Table 3 provides the summary statistics, AVEs, reliability scores, and correlations for the study constructs.

\section{Tests of hypotheses}

We tested the hypothesized links using seemingly unrelated regressions (SUR) in STATA 13.1. ${ }^{5}$ This technique enables the estimation of multiple equations by taking into account the contemporaneous correlation of errors across equations to produce more reliable and efficient estimates (Zellner 1962). We estimated two regression equations for every model tested. Eco-friendly product development strategy and product development effectiveness were the dependent variables for the first and second regression equations, respectively. We report three regression models: Model 1 contains the effects of controls on the two dependent variables, Model 2 includes the direct and control variables effects, and Model 3 adds the effects of the interactions of the three business environment variables with eco-friendly product development strategy. For normalization and estimation purposes, we logarithmically transformed firm size, and to minimize potential multicollinearity, we mean-centered all relevant variables before producing the interaction terms.

The Breusch-Pagan test of independence shows that the error terms between both regression equations for the full model containing the interactions (Model 3 ) are significantly correlated $\left(\chi_{(\mathrm{df}=1)}^{2}=16.33 ; p<0.01\right)$, which justifies the use SUR. The results also suggest the full model has substantial explanatory power, as the $\mathrm{R}^{2}$ was 0.44 for eco-friendly product development strategy and 0.41 for product development effectiveness. The coefficients, $t$-values, standard errors, and

\footnotetext{
${ }^{5}$ We also used SmartPLS 3.2.1 (Ringle et al. 2014) to test our hypotheses. We found no material change in the direction and significance of the hypothesized links, which enhances confidence in our findings.
} 


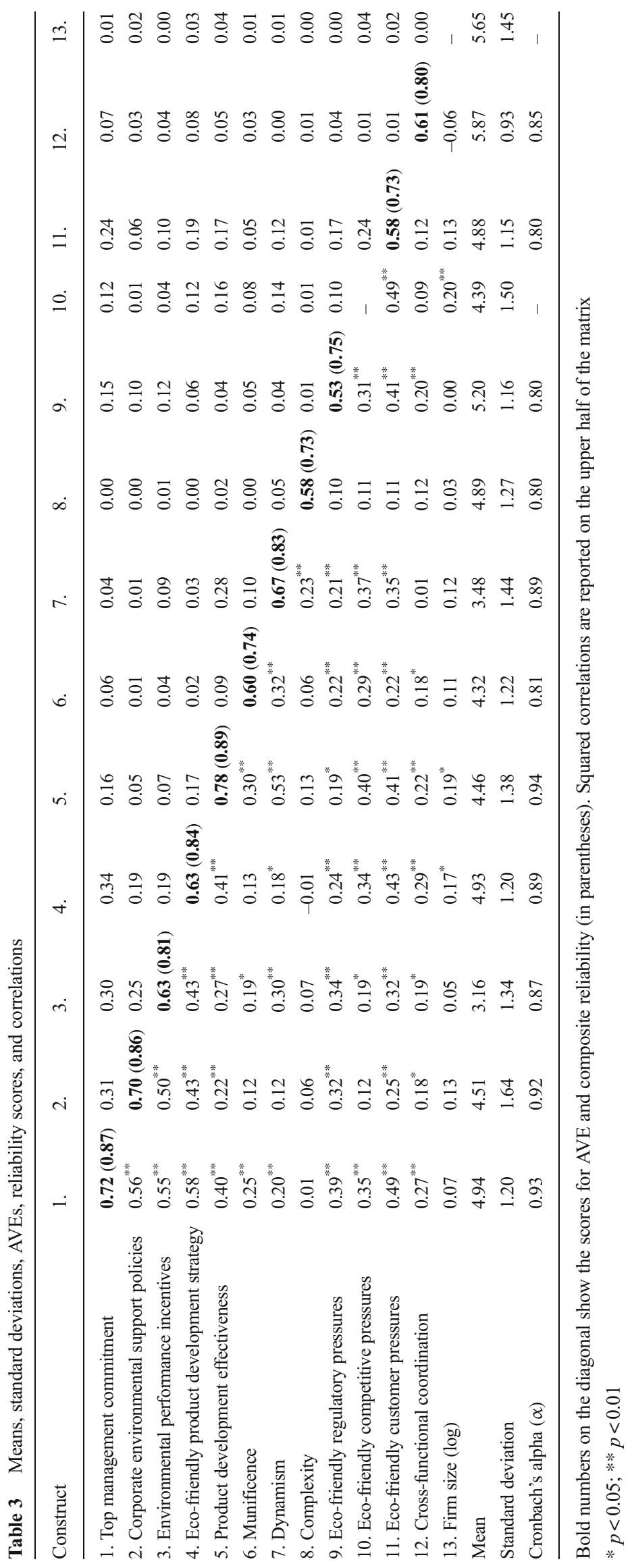


significance levels for the structural paths, along with $\chi^{2}$ and $\mathrm{R}^{2}$ values for each model, appear in Table 4 . Overall, the results indicate that, with the exception of $\mathrm{H} 3$ and $\mathrm{H} 6$, all hypothesized links are significant and in the expected direction. ${ }^{6}$

The analysis shows that top management commitment $(b=0.35, p<0.01)$ and corporate environmental support policies $(b=0.13, p<0.05)$ positively affect eco-friendly product development strategy, in support of $\mathrm{H} 1$ and $\mathrm{H} 2$, respectively. However, the results indicate that environmental performance incentives have no significant effect on eco-friendly product development strategy ( $b=0.04$, n.s.), providing no support for H3. The findings from the analysis also show that an ecofriendly product development strategy at $t_{1}$ enhances product development effectiveness at $t_{2}(b=0.55, p<0.01)$, consistent with H4. Further, the results reveal that the business environment plays an important role in moderating the eco-friendly product development-effectiveness link. Specifically, ecofriendly product development strategy $\times$ munificence crossproduct has a marginally significant positive effect $(b=0.10$, $p<0.10)$ and eco-friendly product development strategy $\times$ complexity cross-product a strong negative effect $(b=-0.13$, $p<0.01$ ) on product development effectiveness, in accord with $\mathrm{H} 5$ and $\mathrm{H} 7$, respectively. However, no significant interaction effect emerged in the case of dynamism $(b=-0.02$, n.s.), lending no support to H6. Figure 2 illustrates the significant interaction effects. ${ }^{7,8}$

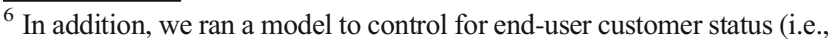
business to consumer, business to business, and both). The dummies were not related to product development effectiveness (at $p<0.10$ ), and the overall pattern and significance of results remained the same.

${ }^{7}$ We used several ex ante procedural remedies suggested by Podsakoff et al. (2003) to control for common method bias. Specifically, we used a time lag between the measurement of eco-friendly product development strategy and product development effectiveness, employed a systematic questionnaire development process, and stressed confidentiality to all respondents. Common method bias was also assessed using a post hoc identification of a marker variable by selecting the second-smallest positive correlation between the study variables (Malhotra et al. 2006). We subsequently adjusted the correlation matrix using this correlation that was between dynamism and cross-functional co-ordination (i.e., $r_{\mathrm{M} 2}=0.009$ ). A comparison of the original and the adjusted correlation matrices revealed that discrepancies in these correlation sets were small and patterns of significance remained the same ( $p<0.05$, two-tailed). These results suggest common method bias is not a serious issue in our study.

${ }^{8}$ Because of the sensitive nature of this topic (i.e., eco-friendly practices) and the institutional pressures surrounding it, we controlled for the possibility of social desirability bias in our study. We undertook two steps to this end. First, we carefully crafted our questionnaire items to avoid any direct references to societal consequences of corporate green practices. Second, we used Ballard's (1992) social desirability scale. High correlations between the social desirability scale and the measures of our study constructs indicate potential response bias. The scale did not significantly correlate with any of the constructs $(p<0.10)$, nor did it materially affect our empirical results when we included the scale in our model. Thus, social desirability bias is unlikely to be an issue of major concern in this research.
}

\section{Self-selection bias}

To control for selection bias in our analyses, we followed Heckman's (1979) two-stage test (e.g., Chen et al. 2009; Kale et al. 2002; Poppo and Zenger 2002). ${ }^{9}$ We applied two probit selection models in IBM SPSS 19 using the full sample of 183 firms to estimate the probability that a firm will achieve low (0) or high (1) product development effectiveness and the company's decision to green its product development strategy (1) or not (0), respectively. We generated the two dichotomous variables using a median split of the product development effectiveness and eco-friendly product development strategy variables. Subsequently, we estimated two regression equations. The first used $\lambda$ along with eco-friendly product development strategy, munificence, dynamism, complexity, cross-functional coordination, and firm size as regressors and product development effectiveness as the dependent variable. The second used eco-friendly product development strategy as the dependent variable and top management commitment, corporate environmental support policies, environmental performance incentives, eco-friendly regulatory pressures, eco-friendly competitive pressures, eco-friendly customer pressures, cross-functional coordination, firm size, and the relevant $\lambda$ as the independent variables. The inclusion of $\lambda$ in each equation provided results consistent with those in our original model (i.e., without $\lambda$ ), while $\lambda$ itself was not a significant predictor of effectiveness or strategy. Collectively, the results suggest self-selection bias is not a particular problem in this study.

\section{Discussion and implications}

Building on Hart's (1995) NRBV of the firm and Lado et al.'s (1992) model of competitive advantage, our theoretical model tests the drivers and outcomes of eco-friendly product development strategies. The findings offer support to the win-win logic of implementing eco-friendly product development strategies and show how certain business environment conditions, namely, complexity and to a lesser extent munificence,

\footnotetext{
${ }^{9}$ The first stage involves the estimation of a probit model that predicts the occurrence of a particular observation (i.e., eco-friendly product development, product development effectiveness) (Kale et al. 2002). A new variable is calculated (i.e., inverse Mills ratio $\lambda$ ) that reflects the effects of all unmeasured phenomena that can explain the dependent variable and predicts whether a particular issue is included or not from the sample (Poppo and Zenger 2002). The second stage involves the estimation of a weighted least squares regression of the focal variable as the dependent variable and all the original independent and control variables, as well as the inverse Mills ratio ( $\lambda$ ), as the independent variables (Kale et al. 2002). A significant $\lambda$ indicates self-selection bias and vice versa (Chen et al. 2009).
} 


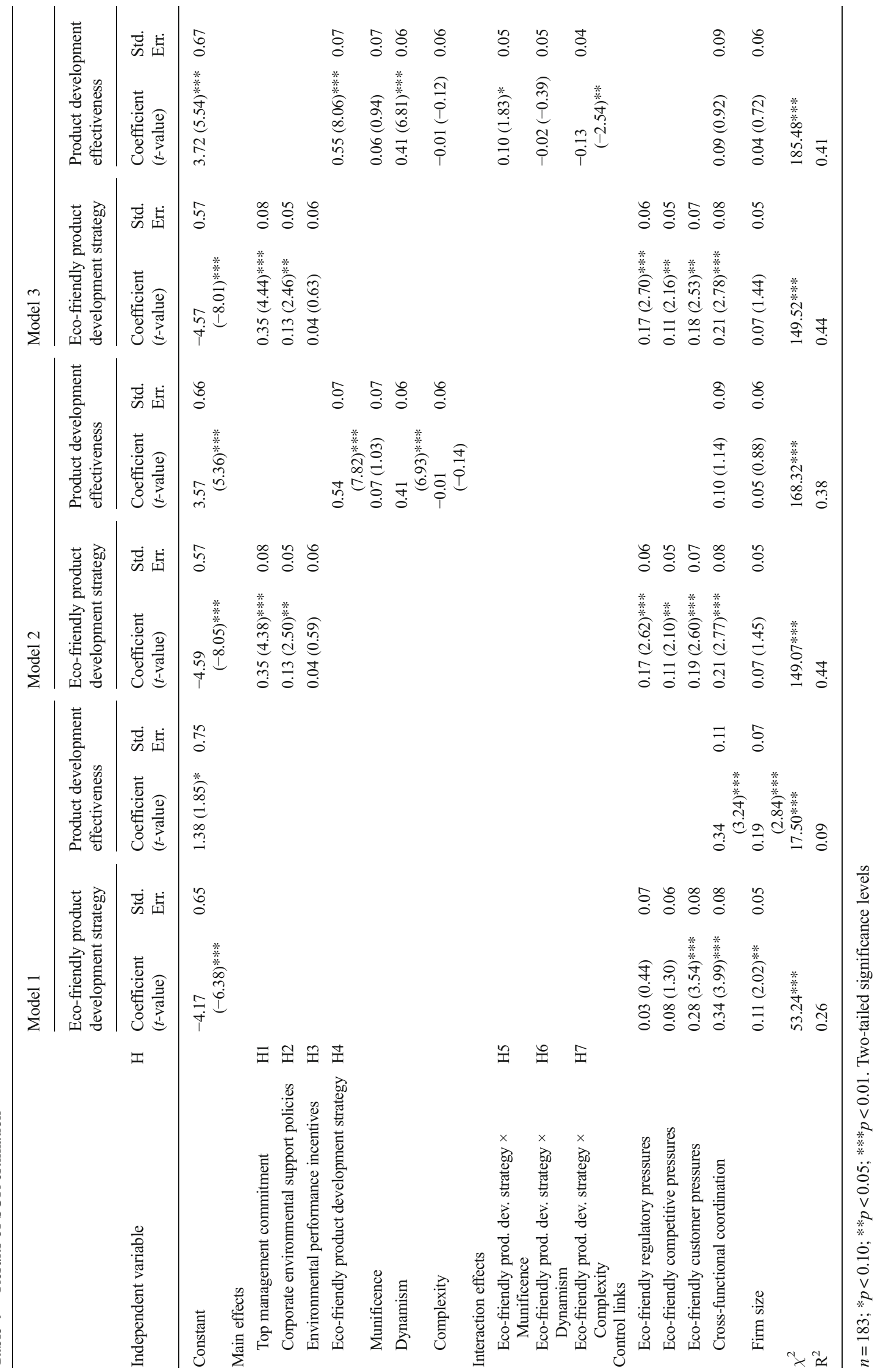


Fig. 2 Analysis of significant interaction effects a

Interaction between munificence and eco-friendly product development strategy on product development effectiveness

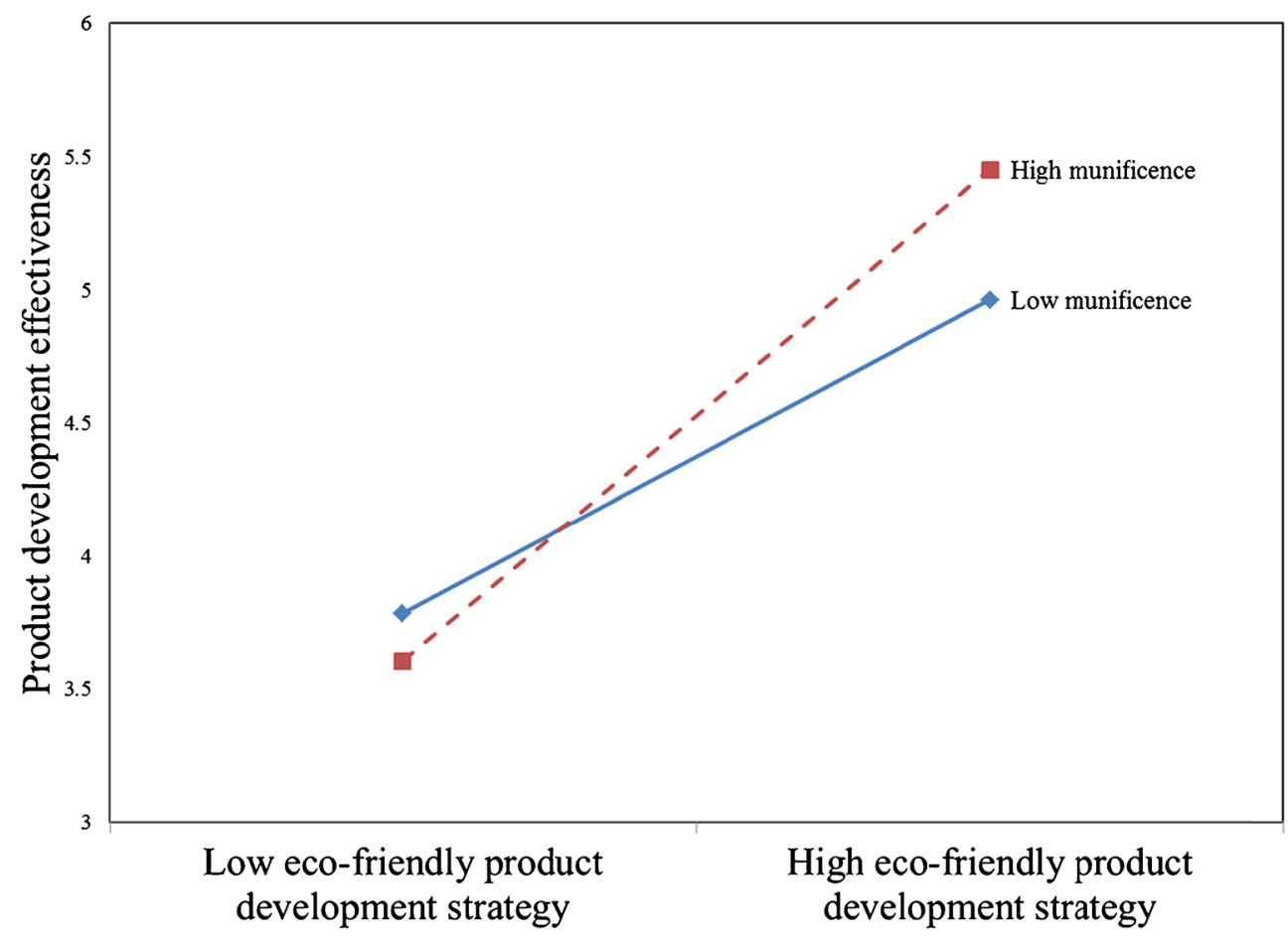

b Interaction between complexity and eco-friendly product development strategy on product development effectiveness

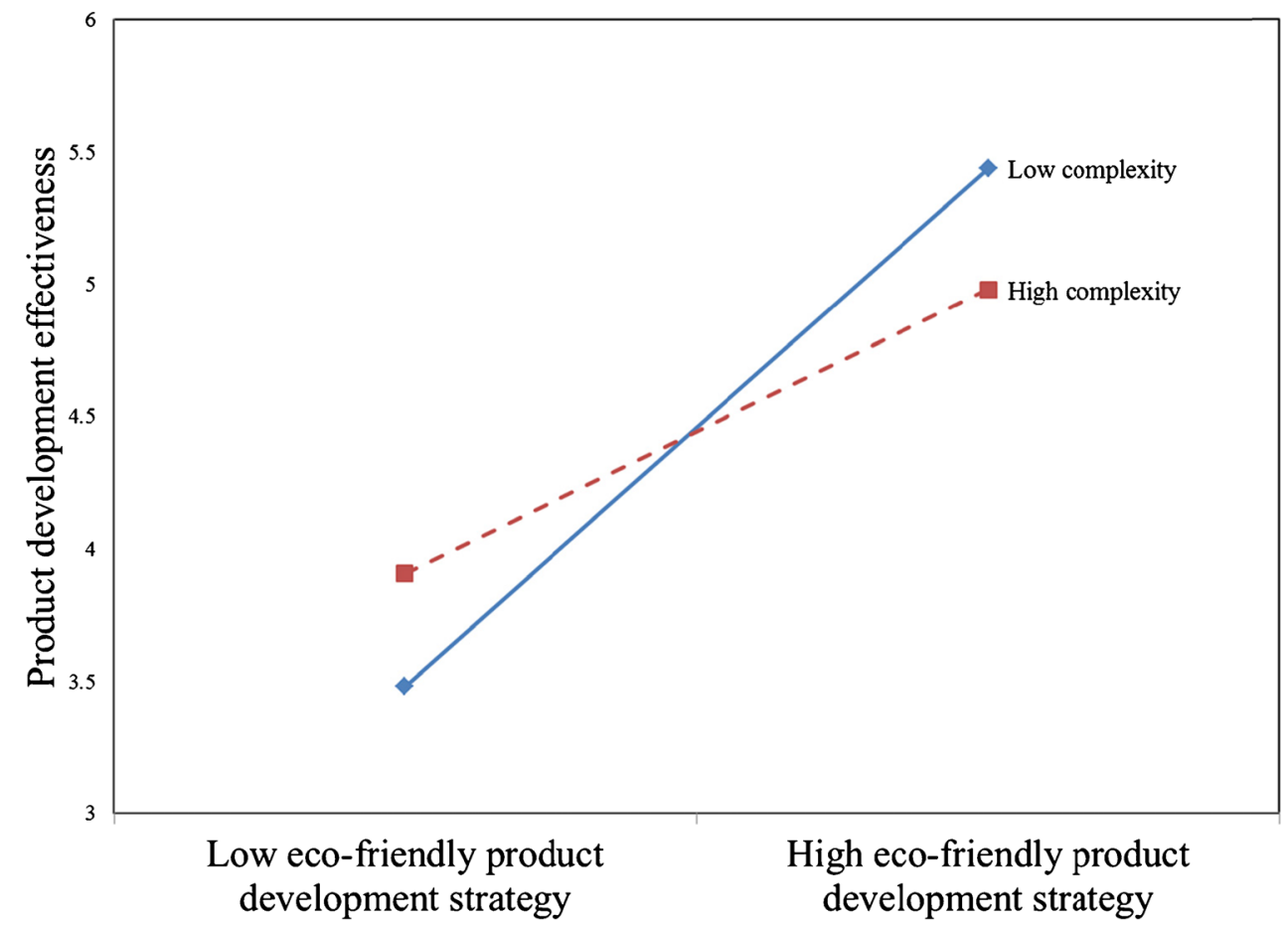

can influence the positive eco-friendly product development strategy outcomes. The study results also uncover the importance of managerial (i.e., top management commitment) and input-based (i.e., corporate environmental support policies) resources for the deployment of transformational organizational capabilities. The results carry important implications 
for future research and offer new insights for managers and policymakers.

This study broadens and deepens understanding of the importance of environmental sustainability for the firm's performance. Previous studies on sustainability (e.g., Fraj-Andrés et al. 2009; Menguc et al. 2010) have identified positive outcomes of environmental strategies for firms' customer satisfaction and product-market and financial performance. However, it has been argued that a more thorough understanding of the effect of green marketing and innovation strategies on firm performance is required (Cronin et al. 2011). We add to this stream of studies by focusing on the long-standing debate about performance outcomes of environmental marketing practices and, specifically, on eco-friendly product development strategies and their implications for product development effectiveness. We uncover the nature of eco-friendly product development strategy as a driver of product development effectiveness and shed light on the moderating role of the business environment in this context. Our results show that the adoption of an eco-friendly product development strategy as a transformational capability can enhance the effectiveness of the firm's product development function.

Given the cross-sectional nature of empirical studies on the performance outcomes of environmental strategies, scholars have repeatedly called for research incorporating a time separation between dependent and independent variables to discern causality and eliminate alternative explanations for relationships between such strategies and performance (e.g., De Ruyter et al. 2009; González-Benito and González-Benito 2005). Our study extends existing knowledge by incorporating a 1-year time lag into the examination of eco-friendly product development strategy's effects on product development effectiveness. Pragmatically, the outcomes of such ecofriendly strategies require time to materialize. The use of such a lag reflects an effort to unveil the fundamental nature of the eco-friendly product development strategy-product development effectiveness association by considering the time interval between the existence of causes and the demonstration of effects. Our approach is a marked improvement over studies examining environmental strategy outcomes using crosssectional data and an incremental step in better understanding the dynamic nature of such linkages.

The findings indicate that the effect of eco-friendly product development on product development effectiveness becomes weaker when the environment in which the firm operates is complex. In complex business environments, firms tend to make limited adjustments to their product strategies, to be hesitant to undertake large product development investments, and to avoid radical and in-depth product changes (AragonCorrea and Sharma 2003). In contrast with complexity, which puts the brake on these outcomes, the presence of munificence in the business environment might accelerate the effectiveness outcomes of eco-friendly product development. Though the effect revealed was marginally significant $(p<0.10)$, there are signs that the link between eco-friendly product development strategy and product development effectiveness tends to be stronger for firms operating in highly munificent environments. Perhaps this is because market growth can help firms reduce the level of risk associated with environmental practices and generate sustainability-led innovations. This result is also in line with Russo and Fouts's (1997) assertion that environmental initiatives have better performance prospects in high-growth industries. Collectively, these results provide new evidence of the importance of the business environment in materializing the business case for eco-friendly strategies.

Whereas most extant work on the drivers of eco-friendly product development strategies has centered on individual projects, we extend recent research on the subject by focusing on the organizational level in response to calls for such investigations (e.g., Dangelico and Pujari 2010). The results confirm that top management commitment to environmental sustainability and the establishment of rigorous environmental support policies are key factors conducive to the deployment of eco-friendly product development strategic capability. These factors can serve as valuable input resources in developing transformational capabilities and may be perceived as strong mobilizing forces in stimulating the integration of environmental issues into product development. Green product practices are often viewed as complex, costly, and risky (Sharma 2000); require technical and highly specialized capabilities (Boiral 2002); and entail substantial changes in product development operations (Dangelico and Pujari 2010). Deployment of environmental support policies may be viewed as a resource that enables employees to address technical challenges, making the whole process easier to implement. Likewise, support by top management helps unlock the resources needed to invest in eco-friendly product development.

The study also reveals the lack of a significant effect of environmental performance incentives on eco-friendly product development strategy. It seems that in the U.K. context, environmental performance incentives are not popular or effective enough. While their ineffectiveness is reflected in the non-significant finding, their limited popularity is evidenced by the relatively low mean respondent score for such incentives $(\mathrm{M}=3.16, \mathrm{SD}=1.34)$. In view of this somewhat surprising finding, we conducted post hoc interviews with managers to investigate this further. The interviews suggested that, though environmental incentives were considered potentially useful for greening a firm's operations, in practice they were not popular among companies and employees. Further, because the provision of such incentive and reward schemes is at an early phase, their deployment may not be effective enough to motivate employees to change traditional product development practices. Relatedly, Pagell and Wu (2009) report the absence of measurement and reward systems in most firms and emphasize the importance of coherent reward 
structures for effectively integrating environmental issues into firm strategy. Some managers, however, agreed that green incentives could work when top management commitment to environmental investments is limited. This is because the absence of strong support by top management might push employees to seek substitute mechanisms to cope with increasing green stakeholder concerns.

To examine this possibility, we divided the sample into low and high top management commitment groups (median split) and ran our model in each group. We found that the impact of environmental performance incentives on eco-friendly product development strategy is significant when top management commitment is low $(\beta=0.30, p<0.05)$ but has no effect when top management commitment is high $(\beta=0.04$, n.s.). This implies that the positive effect of environmental performance incentives on eco-friendly product development strategy is diminished when the firm has high top management commitment, while the latter might substitute top management commitment as enabler of eco-friendly product development strategy when such commitment is absent within the firm. However, this evidence is tentative in nature, and thus additional research is necessary to explore the roles of environmental performance incentives and top management commitment in influencing sustainable product practices and performance.

\section{Implications for managers and public policymakers}

Managers today are increasingly being pressured by various stakeholders to find ways to integrate environmental aspects in product development (Dangelico et al. 2013). Indeed, many companies have embraced the idea of environmental sustainability, while others are still searching for the business case to take this forward. Our study provides insights into its importance for the firm in propelling effectiveness in product development. To enhance effectiveness, managers should focus on building a strategic capability in eco-friendly product development. Such a capability enables firms not only to satisfy market-based stakeholders and minimize the ecological impact of product development but also to realize significant product development benefits in terms of product quality enhancement, new product introductions improvement, and product success rate enhancement.

Our data show that the effectiveness of an eco-friendly product development strategy depends on the levels of complexity and to a lesser extent munificence in the firm's business environment. Marketing practitioners can gain advantages in deploying eco-friendly product development strategies when favorable market opportunities for growth exist. In such business environments, eco-friendly product development strategies can contribute to successful product development operations and foster innovation within the firm. However, managers should be aware that when business environment conditions are highly complex, eco-friendly product development strategies may not be rewarding enough to justify investments in deploying such strategies.

To better understand the direct and moderating effects on product development effectiveness, we conducted two post hoc analyses. First, using a median split we found that firms with a higher eco-friendly product development strategy achieved, on average, $21.3 \%$ higher product development effectiveness. Similarly, examining eco-friendly product development strategy using quartiles shows that firms in the upper quartile exhibit stronger product development effectiveness results by $31.0 \%$, than those in the lower quartile. Second, we divided our sample into high (top quartile) and low (bottom quartile) groups for each of the significant moderating variables. We then compared the average product development effectiveness scores across high (top 25\%) versus low (bottom 25\%) eco-friendly product development strategy groups. Firms operating in highly munificent environments (top $25 \%$ of munificence) achieved $15.4 \%$ greater product development effectiveness when these also had high versus low eco-friendly product development strategies. Similarly, firms in low munificent environments achieved greater product development effectiveness when eco-friendly strategy was high rather than low. However, the increase in product development effectiveness was lower in this case (i.e., 7.5\%). In addition, firms operating in highly complex environments (top $25 \%$ ) and with a strong eco-friendly product development strategy achieved $4.0 \%$ better product development effectiveness, than firms with a weak strategy (bottom 25\%). Yet, firms in low complexity conditions (bottom 25\%) had $16.3 \%$ better product development effectiveness when their eco-friendly product development strategy was high instead of low. These findings indicate that firms can maximize product development effectiveness improvement when sound green product development strategies are executed in munificent but relatively non-complex business environments.

Our study also demonstrates the significance of strong top management commitment and environmental support policies in deploying eco-friendly product development strategies. Attempts to instill an environmental ethic into product development without these two factors may prove difficult, because their absence from organizational settings can adversely affect people's motivation to engage in eco-friendly product development operations. Concurrently, lack of emphasis on management commitment and environmental support policies may inhibit the development of capacity and experience to support such capabilities in the organization. While management commitment to environmental sustainability is a controllable and relatively fast-to-implement task, investments in environmental support policies (e.g., training, systems, experts) are likely to be more resource demanding and take time to implement (Melnyk et al. 2003). However, in light of the study findings, managers must be cognizant that such investments will eventually pay off through more effective product development activities. 
Finally, our results should also be of interest to public policymakers. First, regulators might find it prudent to communicate the benefits of greening marketing activities based on strategic rather than purely legislative or ethical grounds. By emphasizing that a "doing well by doing good" approach is possible, policymakers can stimulate heightened interest in eco-friendly practices among organizations. Second, the study highlights the importance of corporate environmental support policies in fostering eco-friendly product development strategies. Government administrators can assist firms lacking environmental support policies by providing technical expertise, organizing knowledge-based sustainability training programs across industries, and offering assistance in installing voluntary environmental policies and procedures. Third, although we found that environmental incentives were not related to eco-friendly product development, our post hoc analysis reveals that such schemes pay off when institutional environmental support is lacking. Thus, in such situations, it might be useful for policymakers to provide financial assistance and recognize excellence in sustainability in an effort to stimulate green product development.

\section{Limitations and future research directions}

The results should be interpreted in light of several limitations inherent in our research design choices. First, we conducted our study in the context of six major industries in the United Kingdom. Replication studies in other countries and industries with different characteristics would test the external validity of our findings. Second, we collected data using single informants. Although in some cases we managed to gather data from a second informant, providing high inter-rater correlations, the potential for key informant bias remains. Future studies could use multi-informants and secondary data sources to validate our results. Third, while we used lagged primary data to assess the impact of eco-friendly product development on effectiveness, we examined drivers of such product development using cross-sectional data. The study remains correlational in nature and the results should be tempered with caution. Further research might pursue an experimental research design or engage in fully fledged longitudinal examinations with all constructs measured at different points in time. Thus, additional insights can be revealed into the dynamics of causality between the study constructs. Fourth, our study examined moderating influences of the business environment on the impact of eco-friendly product development strategy on product development effectiveness. Nonetheless, intervening factors might exist in this relationship, including network externalities, external integrative capabilities, and organizational learning. Examining the effects of such intervening factors would be an intriguing research avenue.

Our results also suggest directions for marketing, management, and product development researchers. First, our study considers three internal drivers of eco-friendly product development. It would be useful to expand not only on the role of these drivers in influencing other elements (e.g., sustainable purchasing, distribution, operations) but also on how the presence of an overall environmental strategy within the firm can determine internal policies and practices (e.g., environmental performance incentives) and lower-level strategies (e.g., ecofriendly product development). Second, in light of the global nature of sustainability issues (Varadarajan 2014), it would be enlightening for research to examine eco-friendly product development in an international setting. Further research could consider issues pertaining to standardization or adaptation of eco-friendly product development strategy (e.g., Zeriti et al. 2014), effects of cross-cultural differences in sustainable product development and innovation implementation (e.g., Kumar 2014), and implications of sustainability considerations for base-of-the pyramid producers (e.g., Adekambi et al. 2015). Third, given our focus on certain key external business environment factors as moderators one potential research avenue would be to examine the conditioning role of internal factors, such as corporate orientations (e.g., environmental, stakeholder) and philosophies (e.g., quality control, just-in-time production).

Finally, our study revealed no significant moderating effect of dynamism in the business environment on the eco-friendly product development-effectiveness link. This might be attributed to the contrasting views of the conditioning role of dynamism that may yield offsetting effects. On the one hand, high dynamism may add difficulty to the adoption and integration of environmental ideas, but on the other hand, firms may boost efforts to find new ways of satisfying changing customer preferences and outperforming competition. Another possible explanation is associated with our focus on a global conceptualization and assessment of eco-friendly product development strategy. The conditioning effects of dynamism may depend on whether the firm pursues exploratory, exploitative, or ambidextrous eco-friendly product innovation and development practices; examination of this issue would certainly be an intriguing future research opportunity.

Acknowledgments The authors would like to thank the Editor and the three anonymous reviewers for their constructive comments and guidance during the review process. The authors would also like to thank Leonidas C. Leonidou (University of Cyprus), Bulent Menguc (Kadir Has University), and Neil A. Morgan (Indiana University) for their constructive suggestions on previous drafts of this article.

Open Access This article is distributed under the terms of the Creative Commons Attribution 4.0 International License (http:// creativecommons.org/licenses/by/4.0/), which permits unrestricted use, distribution, and reproduction in any medium, provided you give appropriate credit to the original author(s) and the source, provide a link to the Creative Commons license, and indicate if changes were made. 


\section{References}

Achrol, R. S., \& Etzel, M. J. (2003). The structure of reseller goals and performance in marketing channels. Journal of the Academy of Marketing Science, 31, 146-163.

Achrol, R. S., \& Stern, L. W. (1988). Environmental determinants of decision-making uncertainty in marketing channels. Journal of Marketing Research, 25, 36-50.

Adekambi, S. A., Ingenbleek, P. T., \& van Trijp, H. C. (2015). Integrating producers at the base of the pyramid with global markets: a market learning approach. Journal of International Marketing, 23, 44-63.

Ambec, S., \& Lanoie, P. (2008). Does it pay to be green? A systematic overview. Academy of Management Perspectives, 22, 45-62.

Anderson, J. C., \& Gerbing, D. W. (1988). Structural equation modeling in practice: a review and recommended two-step approach. Psychological Bulletin, 103, 411-423.

Angell, L. C., \& Klassen, R. D. (1999). Integrating environmental issues into the mainstream: an agenda for research in operations management. Journal of Operations Management, 17, 575-598.

Aragon-Correa, J. A., \& Sharma, S. (2003). A contingent resource-based view of proactive corporate environmental strategy. Academy of Management Review, 28, 71-88.

Ballard, R. (1992). Short forms of the Marlowe-Crowne social desirability scale. Psychological Reports, 71, 1155-1160.

Banerjee, S. B., Iyer, E. S., \& Kashyap, R. K. (2003). Corporate environmentalism: antecedents and influence of industry type. Journal of Marketing, 67, 106-122.

Barney, J. (1991). Firm resources and sustained competitive advantage. Journal of Management, 17, 99-120.

Baron, R. A., \& Tang, J. (2011). The role of entrepreneurs in firm-level innovation: joint effects of positive affect, creativity, and environmental dynamism. Journal of Business Venturing, 26, 49-60.

Bearden, W. O., \& Netemeyer, R. G. (1998). Handbook of marketing scales (2nd ed.). Thousand Oaks: Sage Publications, Inc.

Berry, M. A., \& Rondinelli, D. A. (1998). Proactive corporate environmental management: a new industrial revolution. Academy of Management Executive, 12, 38-50.

Boiral, O. (2002). Tacit knowledge and environmental management. Long Range Planning, 35, 291-317.

Branzei, O., Ursacki-Bryant, T. J., Vertinsky, I., \& Zhang, W. (2004). The formation of green strategies in Chinese firms: matching corporate environmental responses and individual principles. Strategic Management Journal, 25, 1075-1095.

Chabowski, B. R., Mena, J. A., \& Gonzalez-Padron, T. L. (2011). The structure of sustainability research in marketing, 1958-2008: a basis for future research opportunities. Journal of the Academy of Marketing Science, 39, 55-70.

Chang, C. H. (2011). The influence of corporate environmental ethics on competitive advantage: the mediation role of green innovation. Journal of Business Ethics, 104, 361-370.

Chen, C. (2001). Design for the environment: a quality-based model for green product development. Management Science, 47, 250-263.

Chen, Y. S., \& Chang, C. H. (2013). The determinants of green product development performance: green dynamic capabilities, green transformational leadership, and green creativity. Journal of Business Ethics, 116, 107-119.

Chen, Y. S., Lai, S. B., \& Wen, C. T. (2006). The influence of green innovation performance on corporate advantage in Taiwan. Journal of Business Ethics, 67, 331-339.

Chen, Y., Ganesan, S., \& Liu, Y. (2009). Does a firm's product-recall strategy affect its financial value? An examination of strategic alternatives during product-harm crises. Journal of Marketing, 73, 214 226.
Chen, J., Damanpour, F., \& Reilly, R. R. (2010). Understanding antecedents of new product development speed: a meta-analysis. Journal of Operations Management, 28, 17-33.

Cronin, J. J., Jr., Smith, J. S., Gleim, M. R., Ramirez, E., \& Martinez, J. D. (2011). Green marketing strategies: an examination of stakeholders and the opportunities they present. Journal of the Academy of Marketing Science, 39, 158-174.

Daily, B. F., \& Huang, S. C. (2001). Achieving sustainability through attention to human resource factors in environmental management. International Journal of Operations \& Production Management, $21,1539-1552$.

Dangelico, R. M. (2015). Green product innovation: where we are and where we are going. Business Strategy and the Environment, forthcoming.

Dangelico, R. M., \& Pujari, D. (2010). Mainstreaming green product innovation: why and how companies integrate environmental sustainability. Journal of Business Ethics, 95, 471-486.

Dangelico, R. M., Pontrandolfo, P., \& Pujari, D. (2013). Developing sustainable new products in the textile and upholstered furniture industries: role of external integrative capabilities. Journal of Product Innovation Management, 30, 642-658.

Day, G. S. (1994). The capabilities of market-driven organizations. Journal of Marketing, 58, 37-52.

Day, G. S. (2011). Closing the marketing capabilities gap. Journal of Marketing, 75, 183-195.

De Ruyter, K., De Jong, A., \& Wetzels, M. (2009). Antecedents and consequences of environmental stewardship in boundary-spanning B2B teams. Journal of the Academy of Marketing Science, 37, 470 487.

Driessen, P. H., \& Hillebrand, B. (2013). Integrating multiple stakeholder issues in new product development: an exploration. Journal of Product Innovation Management, 30, 364-379.

Drnevich, P. L., \& Kriauciunas, A. P. (2011). Clarifying the conditions and limits of the contributions of ordinary and dynamic capabilities to relative firm performance. Strategic Management Journal, 32, 254-279.

Eppinger, S. (2011). The fundamental challenge of product design. Journal of Product Innovation Management, 28, 399-400.

Etzion, D. (2007). Research on organizations and the natural environment, 1992-present: a review. Journal of Management, 33, 637664.

Fornell, C., \& Larcker, D. F. (1981). Evaluating structural equation models with unobservable variables and measurement error. Journal of Marketing Research, 18, 39-50.

Fraj-Andrés, E., Martinez-Salinas, E., \& Matute-Vallejo, J. (2009). A multidimensional approach to the influence of environmental marketing and orientation on the firm's organizational performance. Journal of Business Ethics, 88, 263-286.

Galeazzo, A., Furlan, A., \& Vinelli, A. (2014). Lean and green in action: interdependencies and performance of pollution prevention projects. Journal of Cleaner Production, 85, 191-200.

Gavronski, I., Klassen, R. D., Vachon, S., \& do Nascimento, L. F. M. (2011). A resource-based view of green supply management. Transportation Research Part E: Logistics and Transportation Review, 47, 872-885.

Golicic, S. L., \& Smith, C. D. (2013). A meta-analysis of environmentally sustainable supply chain management practices and firm performance. Journal of Supply Chain Management, 49, 78-95.

González, F. J. M., \& Palacios, T. M. B. (2002). The effect of new product development techniques on new product success in Spanish firms. Industrial Marketing Management, 31(3), 261-271.

González-Benito, J., \& González-Benito, Ó. (2005). Environmental proactivity and business performance: an empirical analysis. Omega, 33, 1-15. 
Govindarajulu, N., \& Daily, B. F. (2004). Motivating employees for environmental improvement. Industrial Management \& Data Systems, 104, 364-372.

Hair, J. F., Jr., Black, W. C., Babin, B. J., Anderson, R. E., \& Tatham, R. L. (2006). Multivariate data analysis (6th ed.). New Jersey: Prentice-Hall International, Inc.

Hart, S. L. (1995). A natural-resource-based view of the firm. Academy of Management Review, 20, 986-1014.

Hart, S. L., \& Dowell, G. (2011). Invited editorial: a natural-resourcebased view of the firm fifteen years after. Journal of Management, $37,1464-1479$.

Hartmann, J., \& Germain, R. (2015). Understanding the relationships of integration capabilities, ecological product design, and manufacturing performance. Journal of Cleaner Production, 92, 196-205.

Heckman, J. J. (1979). Sample selection bias as a specification error. Econometrica: Journal of the Econometric Society, 47, 153-161.

Hopkins, M. S. (2010). How sustainability fuels design innovation. Sloan Management Review, 52, 75-81.

Hult, G. T. M. (2011). Market-focused sustainability: market orientation plus! Journal of the Academy of Marketing Science, 39, 1-6.

Hunt, C. B., \& Auster, E. R. (1990). Proactive environmentalmanagement-avoiding the toxic trap. Sloan Management Review, $31,7-18$.

Jaworski, B. J., \& Kohli, A. K. (1993). Market orientation: antecedents and consequences. Journal of Marketing, 57, 53-70.

Kale, P., Dyer, J. H., \& Singh, H. (2002). Alliance capability, stock market response, and long-term alliance success: the role of the alliance function. Strategic Management Journal, 23, 747-767.

Klassen, R. D., \& McLaughlin, C. P. (1996). The impact of environmental management on firm performance. Management Science, 42, 1199-1214.

Kleinschmidt, E. J., De Brentani, U., \& Salomo, S. (2007). Performance of global new product development programs: a resource-based view. Journal of Product Innovation Management, 24, 419-441.

Kotler, P. (2011). Reinventing marketing to manage the environmental imperative. Journal of Marketing, 75, 132-135.

Koufteros, X. A., Vonderembse, M. A., \& Doll, W. J. (2002). Integrated product development practices and competitive capabilities: the effects of uncertainty, equivocality, and platform strategy. Journal of Operations Management, 20, 331-355.

Kozlenkova, I. V., Samaha, S. A., \& Palmatier, R. W. (2014). Resourcebased theory in marketing. Journal of the Academy of Marketing Science, 42, 1-21.

Kumar, V. (2014). Understanding cultural differences in innovation: a conceptual framework and future research directions. Journal of International Marketing, 22, 1-29.

Lado, A. A., \& Wilson, M. C. (1994). Human resource systems and sustained competitive advantage: a competency-based perspective. Academy of Management Review, 19, 699-727.

Lado, A. A., Boyd, N. G., \& Wright, P. (1992). A competency-based model of sustainable competitive advantage: toward a conceptual integration. Journal of Management, 18, 77-91.

Langerak, F., Peelen, E., \& van der Veen, M. (1998). Exploratory results on the antecedents and consequences of green marketing. Journal of the Market Research Society, 40, 323-335.

Lawrence, P. R., \& Lorsch, J. W. (1967). Organization and environment: Managing differentiation and integration. Boston: Division of Research, Graduate School of Business Administration, Harvard University.

Leonidou, C. N., Katsikeas, C. S., \& Morgan, N. A. (2013). "Greening" the marketing mix: do firms do it and does it pay off? Journal of the Academy of Marketing Science, 41, 151-170.

Lockett, A., \& Wright, M. (2005). Resources, capabilities, risk capital and the creation of university spin-out companies. Research Policy, 34, $1043-1057$.
Low, G. S., \& Mohr, J. J. (2001). Factors affecting the use of information in the evaluation of marketing communications productivity. Journal of the Academy of Marketing Science, 29, 70-88.

Mahoney, J. T. (1995). The management of resources and the resource of management. Journal of Business Research, 33, 91-101.

Malhotra, N. K., Kim, S. S., \& Patil, A. (2006). Common method variance in IS research: a comparison of alternative approaches and a reanalysis of past research. Management Science, 52, 1865-1883.

Matos, S., \& Hall, J. (2007). Integrating sustainable development in the supply chain: the case of life cycle assessment in oil and gas and agricultural biotechnology. Journal of Operations Management, 25, $1083-1102$.

Melnyk, S. A., Sroufe, R. P., \& Calantone, R. (2003). Assessing the impact of environmental management systems on corporate and environmental performance. Journal of Operations Management, 21, 329-351.

Mena, J. A., \& Chabowski, B. R. (2015). The role of organizational learning in stakeholder marketing. Journal of the Academy of Marketing Science, 43, 429-452.

Menguc, B., Auh, S., \& Ozanne, L. (2010). The interactive effect of internal and external factors on a proactive environmental strategy and its influence on a firm's performance. Journal of Business Ethics, 94, 279-298.

Menon, A., \& Menon, A. (1997). Enviropreneurial marketing strategy: the emergence of corporate environmentalism as market strategy. Journal of Marketing, 61, 51-67.

Miller, D., \& Friesen, P. H. (1983). Strategy-making and environment: the third link. Strategic Management Journal, 4, 221-235.

Mitra, S., \& Datta, P. P. (2014). Adoption of green supply chain management practices and their impact on performance: an exploratory study of Indian manufacturing firms. International Journal of Production Research, 52, 2085-2107.

Montabon, F., Sroufe, R., \& Narasimhan, R. (2007). An examination of corporate reporting, environmental management practices and firm performance. Journal of Operations Management, 25, 998-1014.

Nidumolu, R., Prahalad, C. K., \& Rangaswami, M. R. (2009). Why sustainability is now the key driver of innovation. Harvard Business Review, 87, 56-64.

Orlitzky, M., Schmidt, F. L., \& Rynes, S. L. (2003). Corporate social and financial performance: a meta-analysis. Organization Studies, 24, 403-441.

Pagell, M., \& Wu, Z. (2009). Building a more complete theory of sustainable supply chain management using case studies of 10 exemplars. Journal of Supply Chain Management, 45, 37-56.

Paillé, P., Chen, Y., Boiral, O., \& Jin, J. (2014). The impact of human resource management on environmental performance: an employeelevel study. Journal of Business Ethics, 121, 451-466.

Podsakoff, P. M., MacKenzie, S. B., Lee, J. Y., \& Podsakoff, N. P. (2003). Common method biases in behavioral research: a critical review of the literature and recommended remedies. Journal of Applied Psychology, 88, 879-903.

Poppo, L., \& Zenger, T. (2002). Do formal contracts and relational governance function as substitutes or complements? Strategic Management Journal, 23, 707-725.

Porter, M. E., \& van der Linde, C. (1995). Green and competitive: ending the stalemate. Harvard Business Review, 73, 120-134.

Pujari, D. (2006). Eco-innovation and new product development: understanding the influences on market performance. Technovation, 26, $76-85$.

Pujari, D., \& Wright, G. (1996). Developing environmentally conscious product strategies: a qualitative study of selected companies in Germany and Britain. Marketing Intelligence \& Planning, 14, 19 28.

Pujari, D., Wright, G., \& Peattie, K. (2003). Green and competitive: influences on environmental new product development performance. Journal of Business Research, 56, 657-671. 
Pujari, D., Peattie, K., \& Wright, G. (2004). Organizational antecedents of environmental responsiveness in industrial new product development. Industrial Marketing Management, 33, 381-391.

Ramus, C. A. (2001). Organizational support for employees: encouraging creative ideas for environmental sustainability. California Management Review, 43, 85-105.

Ramus, C. A., \& Steger, U. (2000). The roles of supervisory support behaviors and environmental policy in employee "ecoinitiatives" at leading-edge European companies. Academy of Management Journal, 43, 605-626.

Renwick, D. W., Redman, T., \& Maguire, S. (2013). Green human resource management: a review and research agenda. International Journal of Management Reviews, 15, 1-14.

Ringle, C. M., Wende, S., \& Becker, J.-M. (2014). Smartpls 3, Hamburg: SmartPLS, Available at http://www.smartpls.com.

Rueda-Manzanares, A., Aragón-Correa, J. A., \& Sharma, S. (2008). The influence of stakeholders on the environmental strategy of service firms: the moderating effects of complexity, uncertainty and munificence. British Journal of Management, 19, 185-203.

Russo, M. V., \& Fouts, P. A. (1997). A resource-based perspective on corporate environmental performance and profitability. Academy of Management Journal, 40, 534-559.

Sarin, S., \& Mahajan, V. (2001). The effect of reward structures on the performance of cross-functional product development teams. Journal of Marketing, 65, 35-53.

Sarkis, J., Gonzalez-Torre, P., \& Adenso-Diaz, B. (2010). Stakeholder pressure and the adoption of environmental practices: the mediating effect of training. Journal of Operations Management, 28, 163-176.

Schreyögg, G., \& Kliesch-Eberl, M. (2007). How dynamic can organizational capabilities be? Towards a dual-process model of capability dynamization. Strategic Management Journal, 28, 913-933.

Sharma, S. (2000). Managerial interpretations and organizational context as predictors of corporate choice of environmental strategy. Academy of Management Journal, 43, 681-697.

Sharma, S., \& Henriques, I. (2005). Stakeholder influences on sustainability practices in the Canadian forest products industry. Strategic Management Journal, 26, 159-180.

Shook, C. L., Ketchen, D. J., Hult, G. T. M., \& Kacmar, K. M. (2004). An assessment of the use of structural equation modeling in strategic management research. Strategic Management Journal, 25, $397-$ 404.

Smart, C., \& Vertinsky, I. (1984). Strategy and the environment: a study of corporate responses to crises. Strategic Management Journal, 5, 199-213.
Sroufe, R. (2003). Effects of environmental management systems on environmental management practices and operations. Production and Operations Management, 12, 416-431.

Tang, Y., Li, J., \& Yang, H. (2015). What I see, what I do: how executive hubris affects firm innovation. Journal of Management, 41, 16981723.

Varadarajan, R. (2014). Toward sustainability: public policy, global social innovations for base-of-the-pyramid markets, and demarketing for a better world. Journal of International Marketing, 22, 1-20.

Varadarajan, R. (2015). Innovating for sustainability: a framework for sustainable innovations and a model of sustainable innovations orientation. Journal of the Academy of Marketing Science, forthcoming.

Wiseman, F., \& Billington, M. (1984). Comment on a standard definition of response rates. Journal of Marketing Research, 21, 336-338.

Wittmann, C. M., Hunt, S. D., \& Arnett, D. B. (2009). Explaining alliance success: competences, resources, relational factors, and resourceadvantage theory. Industrial Marketing Management, 38, 743-756.

Yarbrough, L., Morgan, N. A., \& Vorhies, D. W. (2011). The impact of product market strategy-organizational culture fit on business performance. Journal of the Academy of Marketing Science, 39, 555573.

Yasai-Ardekani, M. (1989). Effects of environmental scarcity and munificence on the relationship of context to organizational structure. Academy of Management Journal, 32, 131-156.

Zellner, A. (1962). An efficient method of estimating seemingly unrelated regressions and tests for aggregation bias. Journal of the American Statistical Association, 57, 348-368.

Zeriti, A., Robson, M. J., Spyropoulou, S., \& Leonidou, C. N. (2014). Sustainable export marketing strategy fit and performance. Journal of International Marketing, 22, 44-66.

Zhu, Q., Sarkis, J., \& Lai, K. H. (2007). Green supply chain management: pressures, practices and performance within the Chinese automobile industry. Journal of Cleaner Production, 15, 1041-1052.

Zhu, Q., Sarkis, J., Cordeiro, J. J., \& Lai, K. H. (2008). Firm-level correlates of emergent green supply chain management practices in the Chinese context. Omega, 36, 577-591.

Zhu, Q., Sarkis, J., \& Lai, K. H. (2012). Examining the effects of green supply chain management practices and their mediations on performance improvements. International Journal of Production Research, 50, 1377-1394. 